\title{
Extensions to the SCDAP/RELAP5 Code for the Modeling of Debris Oxidation and Material Interactions Preliminary Design Report
}

\author{
Larry J. Siefken \\ Kurt L. Davis
}

Published February 1993

\begin{abstract}
Idaho National Engineering Laboratory
EG\&G Idaho, Inc. Idaho Falls, Idaho 83415
\end{abstract}

Prepared for the Division of Systems Research Office of Nuclear Regulatory Research

U.S. Nuclear Energy Commission Washington, DC 20555 Under DOE Idaho Field Office Contract DE-AC07-76ID01570 FIN A6889 


\section{ABSTRACT}

Preliminary designs are proposed for extending the SCDAP/RELAP5 code so that it models (a) the oxidation of slumping fuel rod material and cohesive and porous debris and (b) the interaction of PWR control rod materials with the other materials in a reactor core. These extensions have the purpose of improving the code's calculation of the damage progression and hydrogen production that takes place during the early phase of a severe accident. 


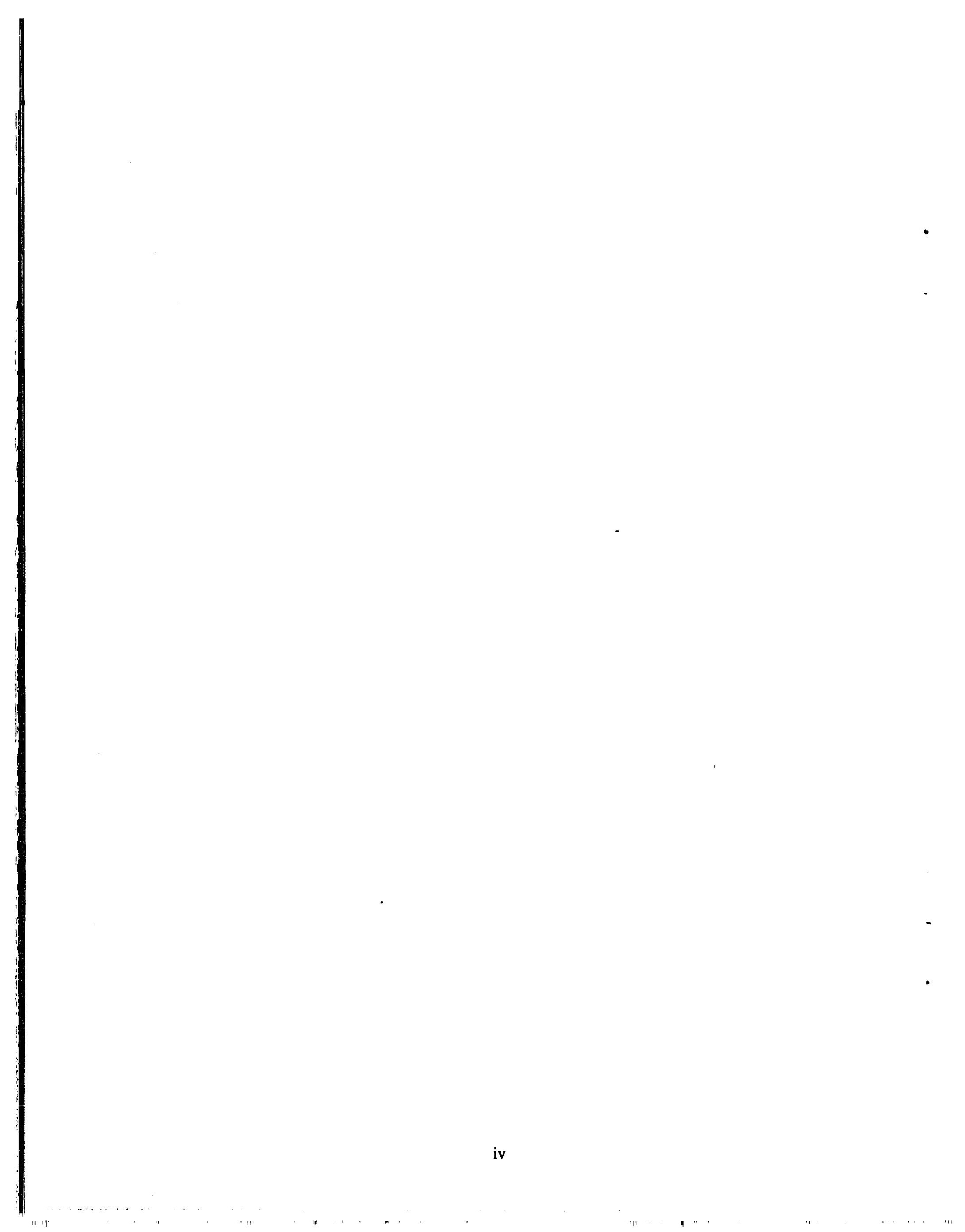




\section{CONTENTS}

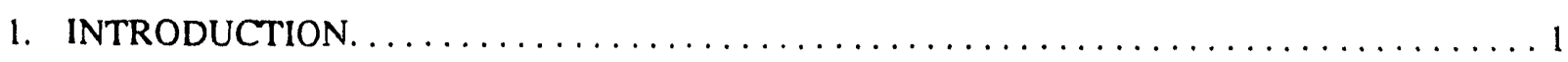

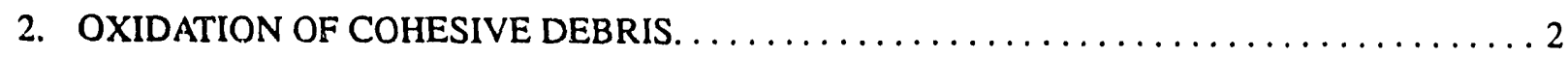

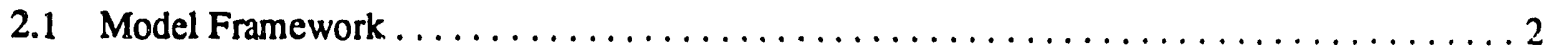

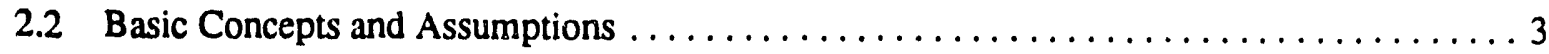

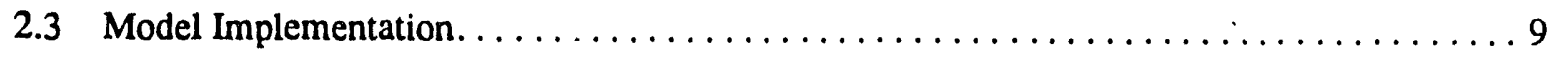

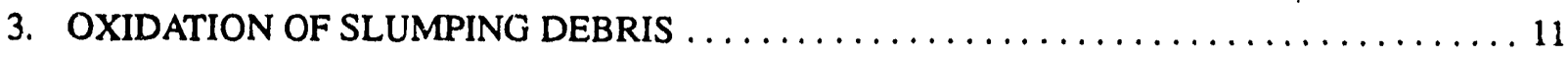

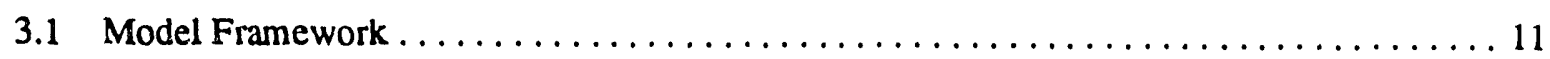

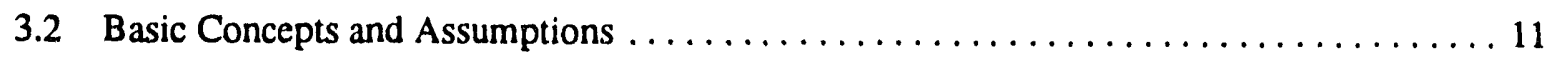

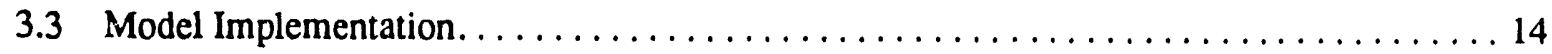

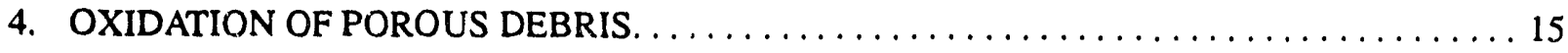

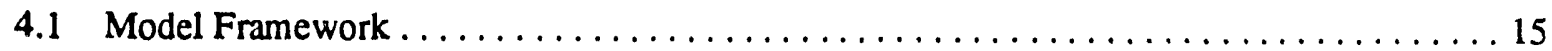

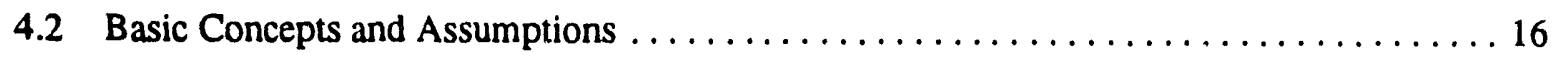

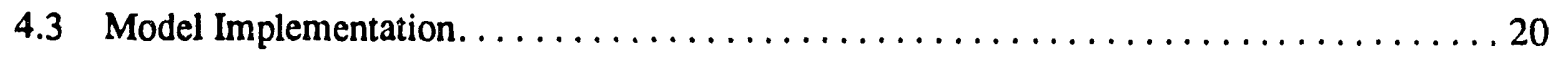

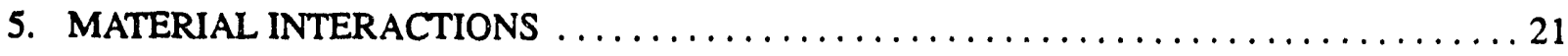

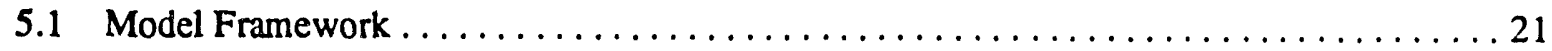

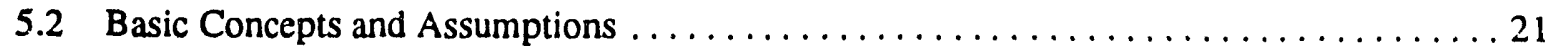

5.3 Model Implementation. . . . . . . . . . . . . . . . . . . . . . . . . 24

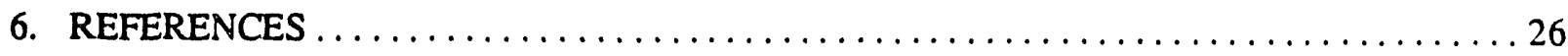




\section{FIGURES}

1. Heat conduction process modeled for cohesive debris. .................. 2

2. Annotated flow chart of model to calculate oxidation of cohesive debris . . . . . . . . . 4

3. Parabolic rate constant for mixture of $85 \mathrm{~mol} \% \mathrm{Zr}$ and $15 \mathrm{~mol}^{2} \mathrm{UO}_{2} \ldots \ldots \ldots \ldots$

4. Content of model for calculating oxidation of slumping debris $\ldots \ldots \ldots \ldots \ldots \ldots \ldots \ldots$

5. Annotated flow chart of the LIQSOL model for calculating overall behavior of slumping material. 2

6. Content of model for oxidation of porous debris $\ldots \ldots \ldots \ldots \ldots \ldots \ldots \ldots \ldots \ldots \ldots$

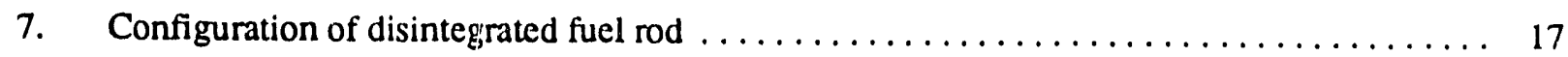

8. Chemical reaction between control rod cladding and guide tube $\ldots \ldots \ldots \ldots \ldots \ldots \ldots 22$

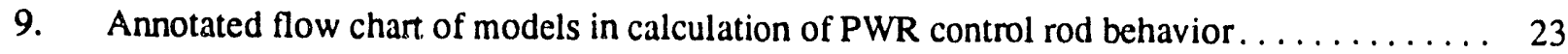

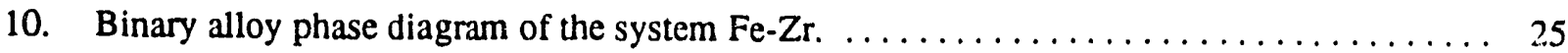




\section{TABLES}

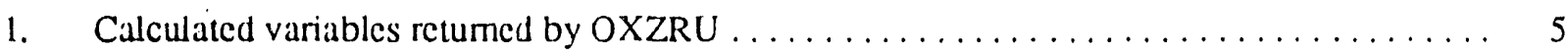

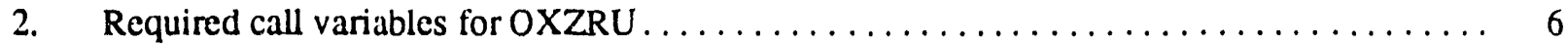




\section{Extensions To The SCDAP/RELAP5 Code For The Modeling Of Debris Oxidation And Material Interactions}

\section{INTRODUCTION}

Preliminary designs are proposed for extending the SCDAP/RELAP5 code so that it models the oxidation of slumping and relocated material and the chemical interaction of pressurized water reactor (PWR) control rod cladding with the guide tube. Debris oxidation results in the release of exothermic heat and hydrogen gas. The chemical reaction caused by the stainless steel control rod cladding contacting the zircaloy guide tube results in a liquefaction and slumping of the control rod. The modeling of these processes will improve the code's calculation of the damage progression and hydrogen production that takes place during the early phase of a severe accident.

The report is divided into six parts. The preliminary design for the modeling of the oxidation of cohesive debris is described in Section 2. The design of the model for the oxidizing of slumping fuel rod material is described in Section 3. The design of a model for calculating the oxidation of porous debris is described in Section 4. The design of a model that calculates the interaction of stainless steel in PWR control rod cladding with the zircaloy guide tube that surrounds it is presented in Section 5. The references are presented in Section 6. 


\section{OXIDATION OF COHESIVE DEBRIS}

This section describes a model with the purpose of calculating the oxidation of fucl rod cladding that has liquetied, slumped, and soliditied at a lower position in the reactor core. Previously, the oxidation of relocated fuel rod cladding was not modeled. As a result, there was the possibility that the SCDAP/ RELAP5 ${ }^{1}$ code could underpredict the hydrogen production during a severe accident. The implementation of this model will resolve this code deficiency.

The impact of the new model will be noticed primarily in the analyses of severe accident sequences in which a significant fraction of the fuel rod cladding slumps and freezes at a lower position in the reactor core. Since the relocated material has a smaller surface-area-to-volume ratio than the cladding in its asfabricated configuration, the rate of hydrogen production of the relocated material is considerably smaller than that in the as-fabricated configuration. Therefore, the new modeling will only impact the calculation of hydrogen production for severe accidents where conditions permit the cohesive debris to oxidize over a long period of time. The new modeling will have no impact on analyses in which slumping of fuel rod cladding is predicted not to occur.

\subsection{Model Framework}

The model for the oxidation of debris will be implemented into the model for calculating the heatup and melt progression of cohesive debris, which is described in Section 3.12 of Reference 1. The framework of the cohesive debris model is shown in Figure 1. The model calculates the axial temperature distribution in cohesive debris as a function of the heat generation in the debris and as a function of the heat transfer from the bottom and top surfaces of the debris. The temperature gradient in the horizontal direction is assumed to be negligible. The model currently neglects oxidation at the bottom and top surfaces of the debris and heat transfer from cohesive debris to the fuel rods that support the cohesive debris. It will be extended to calculate the rate of oxidation at the bottom and top surfaces of the cohesive debris as a function of the temperature of each surface, the availability of steam, and the composition of the material that is oxidizing.

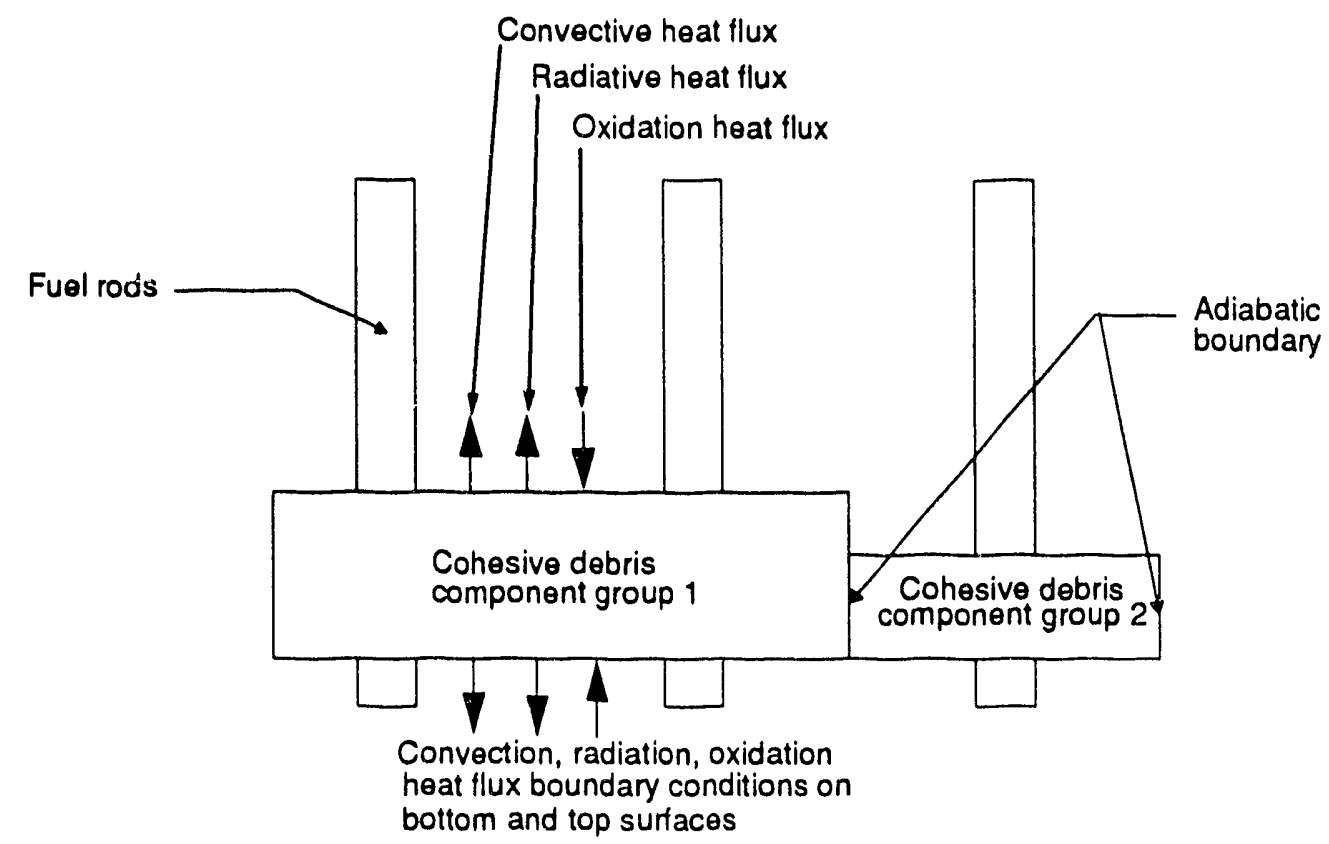

Flgure 1. Heat conduction process modeled for cohesive debris. 
The sequence of calculations that are performed to model the buildup and behavior of cohesive debris are described in the annotated flow chart presented in Figure 2. The first step in the sequence of calculations is to calculate the buildup of the cohesive debris in the reactor core. This calculation is perlormed by the LIQSOL model, which calculates the slumping of liquefied fuel rod material and the location at which this material solidities. The model also calculates the configuration of the solidified material and its composition and the amount of heat generation due to fission products, which changes with time. The second step in the sequence is the calculation of the heat generated in the cohesive debris by oxidation. This calculation will be performed by a subroutine to be developed that will be named OXIAYR. This subroutine first acquires the information necessary for calculating the oxidation of the cohesive debris, which includes the temperature and composition of the bottom and top surfaces and the conditions of the fluid in contact with these surfaces. Then, this subroutine will call a subroutine named OXYDEF to calculate the limits to the rate of oxidation imposed by steam starvation and hydrogen diffusion. It will then call a MATPRO subroutine named OXZRU to calculate the rate of oxidation of the bottom and top surfaces of the cohesive debris. The third step in the sequence is to calculate the temperature change in the cohesive debris that is caused by oxidation and decay heat embedded in it. This calculation is performed by a subroutine named TMPHPN. The calculated change in temperature takes into account the change in fluid conditions at the bottom and top surfaces.

\subsection{Basic Concepts and Assumptions}

Figure 1 shows the configuration of the cohesive debris bed and the heat transfer considered to take place within the debris, including the added oxidation heat flux boundary conditions. The thickness of the debris is constant within each user-defined group of fuel rods. (A fuel rod group is a collection of fuel rods defined by the code user to have identical behavior. The behavior of one representative rod in the group is calculated, and all of the other rods are considered to respond in a like manner.) The temperature gradient in the radial direction in the cohesive debris is assumed to be negligible. Based on this simplifying assumption, the heatup of the cohesive debris within each fuel rod group is calculated, taking into account axial heat conduction and the transfer of heat by convection, radiation, and oxidation from the bottom and top surfaces of the cohesive debris. The internal heat generation in the embedded fuel rods is also taken into account.

The integral method is used to calculate the temperature distribution in the cohesive debris. The temperature distribution is calculated by

$$
\left.\alpha\left[\frac{\partial}{\partial z} T(\delta, t)-\frac{\partial}{\partial z} T(0, t)\right]=\frac{d}{d t}\left[\int_{0}^{\delta} T(z, t) d z\right)\right]-\frac{\delta \dot{q}}{\rho C_{p}}
$$

where

$\begin{array}{lll}\alpha & = & \text { thermal diffusivity of cohesive debris }\left(\mathrm{m}^{2} / \mathrm{s}\right) \\ \delta & = & \text { thickness of cohesive debris }(\mathrm{m}) \\ T(z, t) & = & \text { temperature of cohesive debris }(\mathrm{K}) \\ t & = & \text { time }(\mathrm{s}) \\ z & = & \text { elevation }(\mathrm{m}) ; \mathrm{z}=0=\text { bottom surface of debris; } \mathrm{z}=\delta=\text { top surface } \\ \dot{q} & =\text { volumetric heat generation rate in debris, including heat generation of fuel rods } \\ \rho & =\text { embedded in debris }\left(\mathrm{W} / \mathrm{m}^{3}\right) \\ C \mathrm{p} & =\text { hensity }\left(\mathrm{kg} / \mathrm{m}^{3}\right)\end{array}$




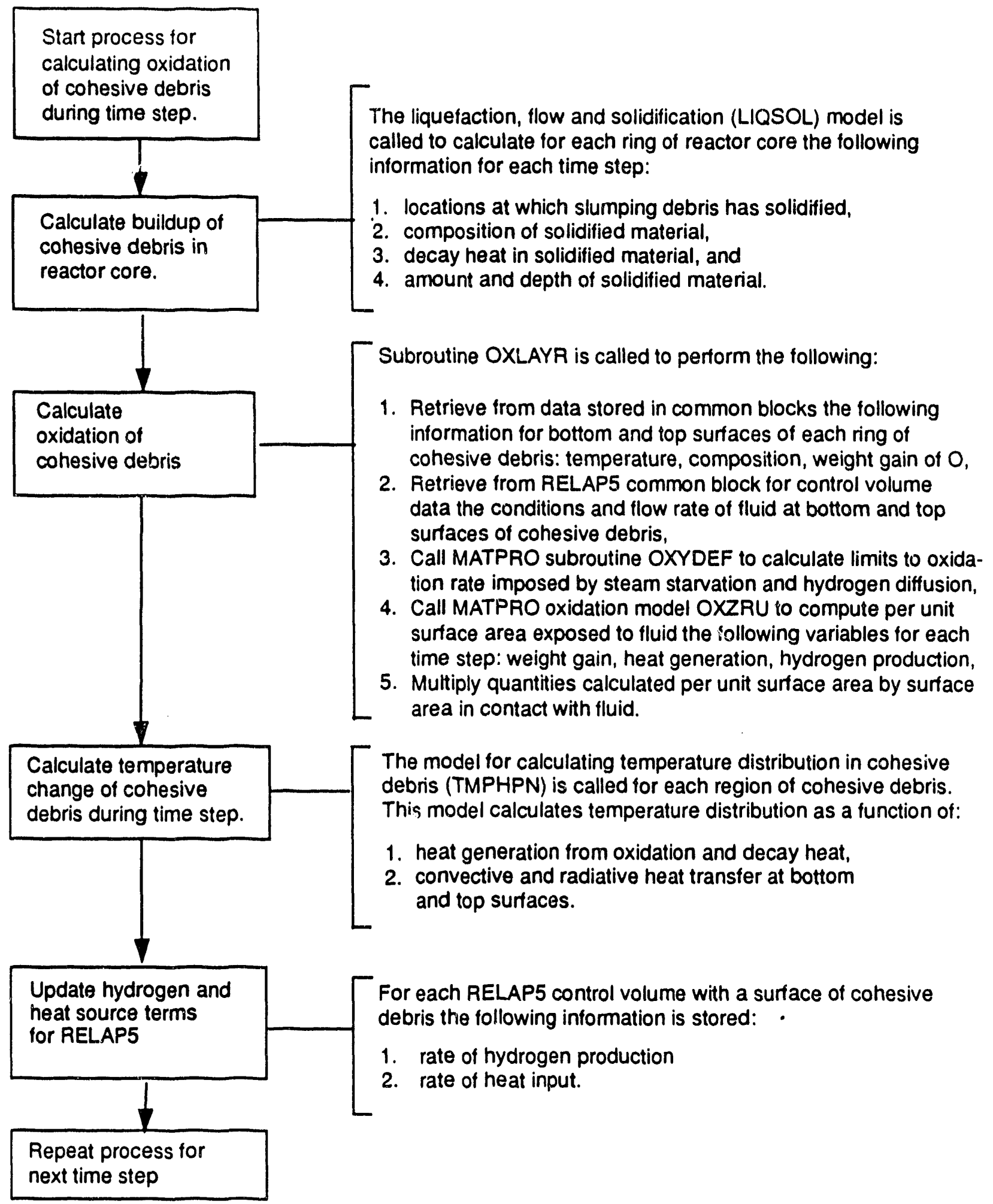

Flgure 2. Annotated flow chart of modcl to calculate oxidation of cohesive debris. 
The boundary conditions applied to Equation (1) are:

$k \frac{\partial}{\partial z} T(0, t)=\varepsilon \sigma\left[T(0, t)^{4}-T_{1}^{4}\right]+h_{1}\left[T(0, t)-T_{1}\right]-Q_{1}$

$k \frac{\partial}{\partial z} T(\delta, t)=\varepsilon \sigma\left[T(\delta, t)^{4}-T_{2}^{4}\right]+h_{2}\left[T(\delta, t)-T_{2}\right]-Q_{2}$

where
$k=$ thermal conductivity $(\mathrm{W} / \mathrm{m} \cdot \mathrm{K})$
$\varepsilon \quad=\quad$ emissivity
$\sigma=$ Stefan-Boltzmann constant $\left(5.668 \mathrm{e}-8 \mathrm{~W} / \mathrm{m}^{2} \cdot \mathrm{K}^{4}\right)$
$T_{1}=$ coolant temperature at bottom surface $(\mathrm{K})$
$T_{2}=\quad$ coolant temperature at top surface $(\mathrm{K})$
$h_{1}=$ convective heat transfer coefficient at bottom surface $\left(\mathrm{W} / \mathrm{m}^{2} \cdot \mathrm{K}\right)$
$h_{2}=$ convective heat transfer coefficient at top surface $\left(\mathrm{W} / \mathrm{m}^{2} \cdot \mathrm{K}\right)$
$Q_{1}=$ oxidation heat flux at bottom surface $\left(\mathrm{W} / \mathrm{m}^{2}\right)$
$Q_{2}=$ oxidation heat flux at top surface $\left(\mathrm{W} / \mathrm{m}^{2}\right)$.

The oxidation heat flux terms, $Q_{1}$ and $Q_{2}$, in Equations (2) and (3) will be calculated by the new cohesive debris oxidation model named OXZRU. The mathematical details of the model are described below.

The OXZRU model calculates the rate of oxidation of a mixture of zircaloy and uranium oxide as a function of several variables. The input variables of the model and their allowable ranges are described in Table 1, and the output variables are described in Table 2. One of the input variables, oxlim, is itself the output of another model. The variable oxlim is the limit on the rate of change in oxygen weight gain. Oxlim is calculated by the model OXYDEF, which calculates the limits imposed on the rate of oxidation by steam availability and hydrogen diffusion. ${ }^{2}$

Table 1. Calculated variables retumed by OXZRU.

\begin{tabular}{ll}
\hline $\begin{array}{c}\text { Variable } \\
\text { name }\end{array}$ & \multicolumn{1}{c}{ Description } \\
\hline oxflux & Oxidation heat flux $\left(\mathrm{W} / \mathrm{m}^{2}\right)$ \\
wgnew & $\begin{array}{l}\text { Total oxygen weight gain at end of time step } \\
\left(\mathrm{kg} / \mathrm{m}^{2}\right)\end{array}$ \\
\hline
\end{tabular}

A major simplification of the OXZRU model is that the cohe ive debris consists only of fuel rod materials, namely $\mathrm{Zr}$ and $\mathrm{UO}_{2}$. The model will not be applicable to the oxidation of cohesive debris that results from the meltdown of PWR or BWR control rods. This debris could include the following materials: stainless steel, $\mathrm{Ag}$, and $\mathrm{B}_{4} \mathrm{C}$. Since debris with these constituents has a significantly lower melting temperature than fuel rod debris, it is expected to slump to a lower and cooler location in the reactor core. 
Table 2. Required call variables for OXZRU.

\begin{tabular}{lll}
\hline \multicolumn{1}{c}{$\begin{array}{c}\text { Variable } \\
\text { name }\end{array}$} & \multicolumn{1}{c}{ Description } & \multicolumn{1}{c}{ Call variable range } \\
\hline tsurf & Surface temperature at beginning of time step $(\mathrm{K})$ & $300(\mathrm{~K})<t s u r f<3000(\mathrm{~K})$ \\
$d t$ & Time step (s) & $0 \leq d t<10(\mathrm{~s})$ \\
wgold & $\begin{array}{l}\text { Total oxygen weight gain at beginning of time step } \\
\left(\mathrm{kg} / \mathrm{m}^{2}\right)\end{array}$ & $0 \leq$ wgold \\
oxlim & $\begin{array}{l}\text { Limit on the rate of change in oxygen weight gain } \\
\left(\mathrm{kg} / \mathrm{m}^{2} \mathrm{~s}\right)\end{array}$ & $0<$ oxlim \\
& Mass fraction of $\mathrm{UO}_{2}$ in zircaloy-uranium mixture & $0 \leq f \leq 1$ \\
\hline
\end{tabular}

where the potential for oxidation is less than that for debris from fuel rods. Therefore, the oxidation of control rod debris is not as important to model as the oxidation of fuel rod debris.

The oxidation of debris is represented as a diffusion-controlled process with a parabolic rate law under isothermal conditions. The oxidation process is represented by the equation

$$
\frac{d w}{d t}=\frac{k_{e f f}}{2 w}
$$

where

$$
\begin{array}{lll}
w & = & \text { oxygen weight gain per unit surface area }\left(\mathrm{kg} \mathrm{O} \mathrm{O}_{2} / \mathrm{m}^{2}\right) \\
t & = & \text { time }(\mathrm{s}) \\
k_{\text {eff }} & = & \text { effective parabolic rate constant for oxygen weight gain }\left[\left(\mathrm{kg} / \mathrm{m}^{2}\right)^{2} / \mathrm{s}\right] .
\end{array}
$$

The integration of Equation (4) with respect to time yields the equation

$w_{1}=\left(k_{e f f} \Delta t+w_{o}^{2}\right)^{0.5}$

where

$$
\begin{array}{lll}
w_{1} & = & \text { weight gain at end of time step }\left(\mathrm{kg} / \mathrm{m}^{2}\right) \\
w_{0} & = & \text { weight gain at start of time step }\left(\mathrm{kg} / \mathrm{m}^{2}\right) \\
\Delta t & = & \text { size of time step }(\mathrm{s}) .
\end{array}
$$

The effective paratolic rate constant is determined by interpolation of experimental data. The parabolic rate constants for debris composed of $100 \% \mathrm{Zr}$ or $100 \% \mathrm{UO}_{2}$ are well-defined by experimental results. For mixtures of $\mathrm{Zr}$ and $\mathrm{UO}_{2}$, however, experimentally determined rate constants are very limited. This limitation of the experimental results makes it necessary to calculate the rate constants for a mixture of $\mathrm{Zr}$ and $\mathrm{UO}_{2}$ based on an assumption of the relation of the rate constants for a mixture to those for $100 \%$ $\mathrm{Zr}$ and $100 \% \mathrm{UO}_{2}$. The assumption has been made that the rate constant changes linearly with change in the mass fraction of $\mathrm{UO}_{2}$ in the mixture. The rate constant will be calculated by the equation 
$k_{e f f}=(1-f) k_{Z r}+f k_{U O_{2}}$

where

$$
\begin{array}{lll}
f & = & \text { mass fraction of } \mathrm{UO}_{2} \text { in mixture } \\
k_{\mathrm{Z}} & = & \text { parabolic rate constant for oxidation of } \mathrm{Zr}\left[\left(\mathrm{kg} / \mathrm{m}^{2}\right)^{2} / \mathrm{s}\right] \\
k_{\mathrm{UO2}} & =\text { parabolic rate constant for oxidation of } \mathrm{UO}_{2}\left[\left(\mathrm{~kg} / \mathrm{m}^{2}\right)^{2} / \mathrm{s}\right]
\end{array}
$$

The rate constant $k_{\mathrm{Z}}$ is calculated as a function of temperature by the COTHK model in MATPRO, and the rate constant $k_{U O}$ is caiculated by the FOXYK model. ${ }^{3}$ Figure 3 shows the results of the model for a mixture of $15 \mathrm{~mol} \% \mathrm{UO}_{2}$ compared to data from Prater-Courtright ${ }^{4}$ for the same mixture. Their experiments are currently the only source of data for a mixture of $\mathrm{U}-\mathrm{Zr}-\mathrm{O}$. The variation between the model results and data at temperatures above $2000 \mathrm{~K}$ is due to the difference between the parabolic rate constants for pure $\mathrm{Zr}$ used in MATPRO (Urbanic-Heidrick for temperatures above $1850 \mathrm{~K}$ ) and those measured by PraterCourtright. Prater-Courtright determined rate constants for pure zircaloy that closely match their data for the $15 \mathrm{~mol} \% \mathrm{UO}_{2}$ mixture except they also noted the discontinuity at $1850 \mathrm{~K}$, which is attributed to the tetragonal-to-cubic phase transformation in $\mathrm{ZrO}_{2}$ with alloying elements.

The fraction of metallic uranium in the mixture of $\mathrm{Zr}$ and dissolved $\mathrm{UO}_{2}$ is assumed to be negligible. Prater and Courtright found that in a mixture of $\mathrm{Zr}-\mathrm{U}-\mathrm{O}$ some of the $\mathrm{U}$ from $\mathrm{UO}_{2}$ diffused as metallic $\mathrm{U}$ along $\mathrm{Zr}$ grain boundaries. ${ }^{4}$ The fraction of $\mathrm{U}$ that behaved in this matter was not identified. Since the fraction of metallic $U$ cannot be defined from experimental results, this fraction will be assumed to be negligible in the modeling of the oxidation of a mixture of $\mathrm{Zr}-\mathrm{U}-\mathrm{O}$.

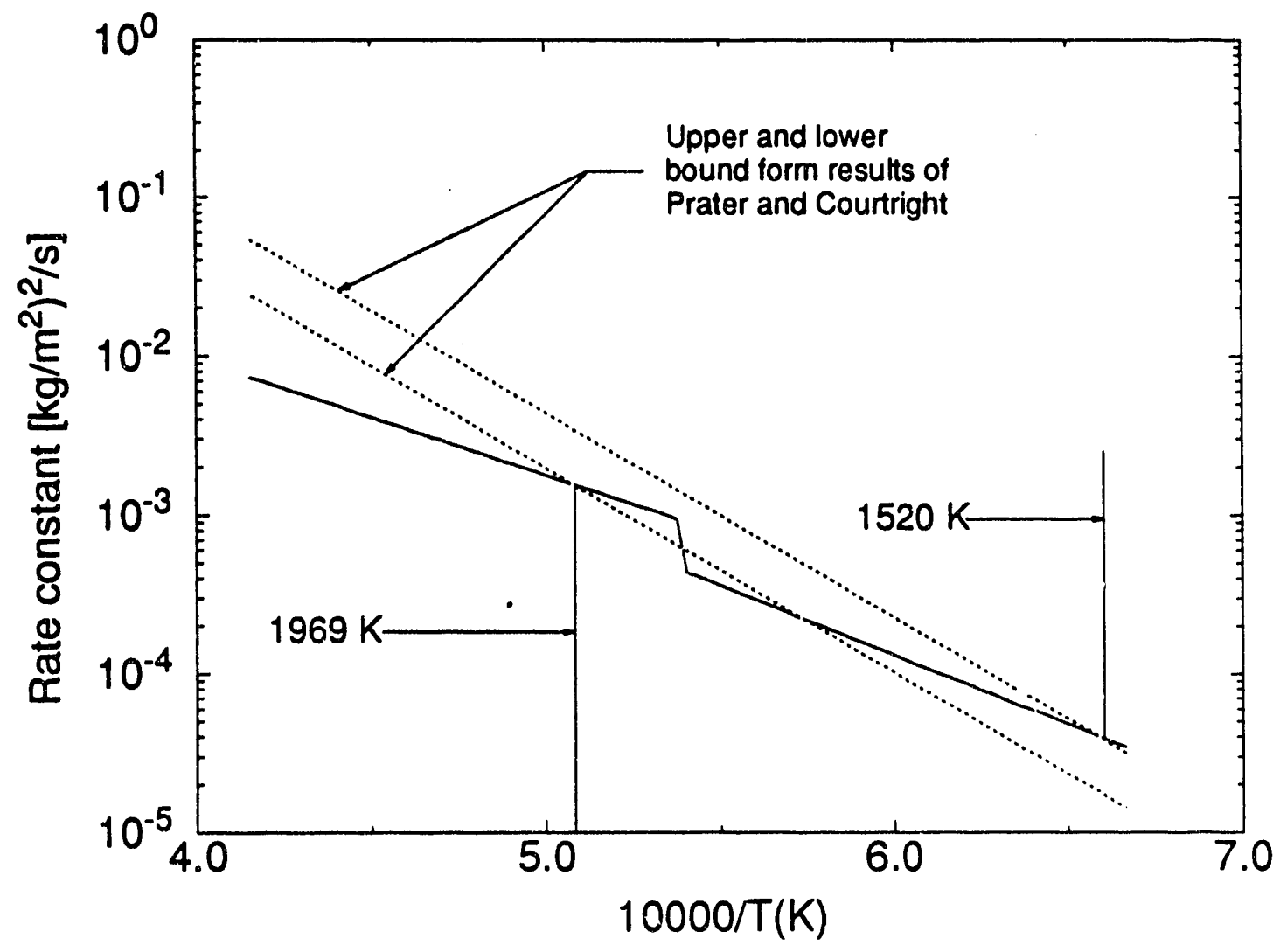

Flgure 3. Parabolic rate constant for mixture of $85 \mathrm{~mol} \% \mathrm{Zr}$ and $15 \mathrm{~mol} \% \mathrm{UU}_{2}$. 
The oxidation heat lux is proportional to the rate at which $\mathrm{Zr}$ in the mixture is converted to $\mathrm{ZrO}_{2}$ and $\mathrm{UO}_{2}$ in the mixture is converted to $\mathrm{U}_{3} \mathrm{O}_{8}$. It is calculated by the equation

$$
Q=\left[(1-f) H_{Z r} \frac{A_{w Z r}}{A_{w O_{2}}}+f H_{U O_{2}} \frac{A_{w U}}{A_{w O_{2}}}\right]\left(\frac{w_{1}-w_{0}}{\Delta t}\right)
$$

where

$$
\begin{array}{lll}
Q & = & \text { oxidation heat flux }\left(\mathrm{W} / \mathrm{m}^{2}\right) \\
H_{\mathrm{Zr}} & = & \text { heat of reaction for } \mathrm{Zr}\left(6.45 \mathrm{e} \mathrm{J} / \mathrm{kg} \text { of } \mathrm{Zr} \text { converted to } \mathrm{ZrO}_{2}\right) \\
A_{w Z r}= & \text { atomic weight of } \mathrm{Zr}(91.22) \\
A_{w O_{2}}= & \text { atomic weight of } \mathrm{O}_{2}(32) \\
H_{U O_{2}}= & \text { heat of reaction for } \mathrm{UO}_{2} \text { as obtained from MATPRO }\left[\mathrm{J} / \mathrm{kg} \text { of }\left(\mathrm{UO}_{2}\right)_{3}\right. \text { converted to } \\
A_{w U}= & \left.\mathrm{U}_{3} \mathrm{O}_{8}\right]
\end{array}
$$

It can be seen from the equation that the zircaloy in the mixture is assumed to be converted to $\mathrm{ZrO}_{2}$ and the $\left(\mathrm{UO}_{2}\right)_{3}$ is assumed to be converted to $\mathrm{U}_{3} \mathrm{O}_{8}$.

The effective oxide layer thickness at the end of the time step is calculated by the equation

$$
h_{1}=\frac{w_{1} \Delta z}{w_{\text {limit }}}
$$

where

$$
\begin{array}{lll}
h_{1}= & \text { thickness of effective oxide layer at end of time step }(\mathrm{m}) \\
w_{\text {limit }}= & \text { upper limit for complete oxidation of the debris bed }\left(\mathrm{kg} / \mathrm{m}^{2}\right) \\
\Delta z & = & \begin{array}{l}
\text { half the debris bed height to allow for independent oxidation of the top and bottom } \\
\text { surfaces }(\mathrm{m}) .
\end{array}
\end{array}
$$

The mass fraction of $\mathrm{UO}_{2}$ in the mixture can be determined from the mass balance on the original rod stubs in the debris bed plus the mass of $\mathrm{UO}_{2}$ relocated into the debris bed. Therefore,

$$
f=\frac{m_{U O_{2}}+m_{U-Z r-o}}{m_{t}}
$$

where

$$
\begin{array}{ll}
m_{U O_{2}}= & \text { mass of } \mathrm{UO}_{2} \text { in the debris bed fuel rod stubs per component }(\mathrm{kg}) \\
m_{U \cdot \mathrm{Zr} \cdot O}= & \text { mass of } \mathrm{UO}_{2} \text { in the melt that has relocated into the debris bed per component }(\mathrm{kg}) \\
m_{t}= & \text { total mass in debris bed per component. }
\end{array}
$$

The initial oxygen weight gain in the upper and lower halves of the debris bed when the debris bed is formed is then 
$w g i n t=\frac{m_{O_{2}}}{2 P^{2}}$

where

$$
\begin{aligned}
& \text { wgint }=\quad \text { initial oxygen weight gain in upper and lower halves of debris bed }\left(\mathrm{kg} / \mathrm{m}^{2}\right) \\
& m_{\mathrm{O}_{2}}=\text { total oxygen in the intact fuel rod stubs and frozen melt }(\mathrm{kg} \mathrm{O}) \\
& P \quad \text { rod pitch }(\mathrm{m}) .
\end{aligned}
$$

The upper limit on the oxygen uptake for each surface is

$v_{\text {limit }}=\frac{\left[\frac{A_{w O_{2}}}{A_{w O_{2}}+A_{Z r}} m_{Z r}+\frac{A_{w O_{2}}}{A_{w O_{8}}+A_{U_{3}}}\left(m_{U O_{2}}+m_{U-Z r-O}\right)\right]}{2 P^{2}}$

where

$$
\begin{array}{ll}
m_{\mathrm{Z}}= & \text { the total mass of unoxidized zircaloy in the fuel rod stubs and } \mathrm{U}-\mathrm{Zr}-\mathrm{O} \text { debris } \\
A_{w O_{8}}= & \text { atomic weight of } \mathrm{O}_{8}(128) \\
A_{U_{3}}= & \text { atomic weight of } \mathrm{U}_{3}(714) .
\end{array}
$$

Equation (11) assumes that the $\mathrm{Zr}$ will oxidize to $\mathrm{ZrO}_{2}$ and the $\left(\mathrm{UO}_{2}\right)_{3}$ will oxidize to $\mathrm{U}_{3} \mathrm{O}_{8}$.

The weight gain of oxygen during the time step must also be less than or equal to oxlim. If all of the material in the mixture is completely oxidized, then the weight gain during a time step is set to zero.

\subsection{Model Implementation}

A new subroutine named OXIAYR will be programmed and implemented into the existing coding that calculates the temperature of cohesive debris. Extensions are also required to the data base of the SCDAP/RELAP5 code in order to store the variables involved in calculating the oxidation of cohesive debris. This section describes the programming and implementation of the new models and the extensions to the data base.

The oxidation of the debris will be programmed in a new subroutine named OXLAYR, which, in turn, will call two subroutines. The first subroutine, named $O X Y D E F,{ }^{2}$ computes the oxidation limit oxlim imposed by the availability of steam and the rate at which oxygen diffuses through a hydrogen blanket. The second subroutine, named OXZRU, calculates the oxidation of a mixture of $\mathrm{Zr}-\mathrm{U}-\mathrm{O}$. Subroutine HEATLD will call subroutine OXLAYR to calculate the heat generated at the surface of the debris during a time step and to calculate the steam consumed and the hydrogen produced by oxidation. The changes in the oxygen weight gain and in the oxide thickness at the surface of the debris layer will also be calculated by subroutine OXIAYR. The subroutine will be called twice, once for the bottom surface and once for the top surface. After the heat generated at the bottom and top surfaces has been calculated, the heat generated by oxidation will be passed to subroutine TMPHPN, where the change in temperature of the cohesive debris during the time step will be computed. This subroutine will be modified to take into account the oxidation heat flux terms in Equations (2) and (3).

The HEATLD subroutine also will be modified to adjust the noncondensable volumetric generation rate to account for the hydrogen produced by oxidation of the cohesive debris layer. The noncondensable 
volumetric generation rate is stored in the variable gaman( $i$, where the index $i$ identifies the RELAP5 control volume and the species of noncondensable gas.

The common block HARDPN will be extended to store variables required for calculating the oxidation of cohesive debris. These additional variables are: (a) $f$, the mass fraction of $\mathrm{UO}_{2}$ in the zircaloyuranium mixture: (b) ivgint, the weight gain in oxygen of the debris at the time of its formation; (c) wgold, the oxygen weight gairi through one surface at the start of the time step; (d) wgnew, same as wgold, but for the end of the time step, and (e) oxlim, a limit on the rate of change of oxygen weight gain due to steam starvation or hydrogen diffusion. Each of the variables will have a dimension of NDCOMP (currently defined in a parameter statement to have a value of 15 ). Since the debris layer can oxidize at both its bottom and top surfaces, two arrays will be defined for each of these six variables, one array for the bottom surface and another array for the top surface. Comment statements will be added to the common block to define each of the variables added to the common block. 


\section{OXIDATION OF SLUMPING DEBRIS}

This section describes a model for calculating the oxidation of liquefied fucl rod cladding that has breached the oxide layer containing it and is slumping. Since the slumping material is very hot (temperature in excess of $2100 \mathrm{~K}$ ) and may have only a thin skin of oxide on its outer surface, this $m$ : erial will oxidize rapidly. Previously, the oxidation of this material was not modeled. As a result, there was the possibility that the SCDAP/RELAP5 code could underpredict the hydrogen production during a severe accident. The implementation of this model is an interim resolution of this code deficiency; the deficiency will not be completely resolved until the slumping material is properly modeled as in the configuration of a rivulet instead of a ring.

\subsection{Model Framework}

The model for the oxidation of slumping debris will be incorporated into the LIQSOL subroutine, which is the subroutine that models the overall behavior of slumping material. The phenomena being calculated by the LIQSOL niodel are shown in Figure 4. If a breach is calculated to occur in the oxide layer on the surface of the fuel rod cladding at a location where the metallic part of the cladding has liquefied and dissolved fuel, then the model calculates the rate of slumping and the thermal response of the liquefied mixture. The model currently neglects the oxidation of the slumping mixture. The model will be extended to calculate the oxidation of the slumping mixture and the affect that oxidation has on the thermal and hydrodynamic response of the slumping mixture. The temperature of the slumping mixture will increase due to oxidation, and the viscosity of the slumping mixture will increase as the metallic part of the mixture is oxidized.

The sequence of calculations that are performed to model the release and slumping of liquefied material is described in the annotated flow chart of the LIQSOL model shown in Figure 5. The first step in the sequence of calculations is to determine the locations at which liquefied material is released during the time step. The second step will be performed by the model for the oxidation of slumping material. This step is currently not being performed. In the third step, the thermal and hydrodynamic response of the slumping mixture is calculated and the location at which it solidifies is determined.

\subsection{Basic Concepts and Assumptions}

Since the current melt relocation model assumes film flow, rather than the rivulet flow and free-falling droplets as shown in bundle heatup and melting experiments in CORA, ${ }^{6}$ the actual surface area for oxidation will not be known. As an interim assumption, it will be assumed that the oxidation of the slumping material occurs at the maximum possible rate, which is that determined by the availability of steam and the rate of hydrogen diffusion. Thus,

$\frac{w_{1}-w_{0}}{\Delta t}=$ oxlim

where oxlim is defined by the OXYDEF routine described in Section 2.3 and Reference 2 . The terms $w_{1}$, $w_{0}$, and $\Delta t$ are the same as those used in Section 2.3. Therefore, the oxidation heat flux can be computed from Equations (7) and (12).

The mass fraction of $\mathrm{UO}_{2}$ in the slumping mixture can be determined from

$\delta=\frac{m_{U-z r-o}}{m_{\imath}}$ 


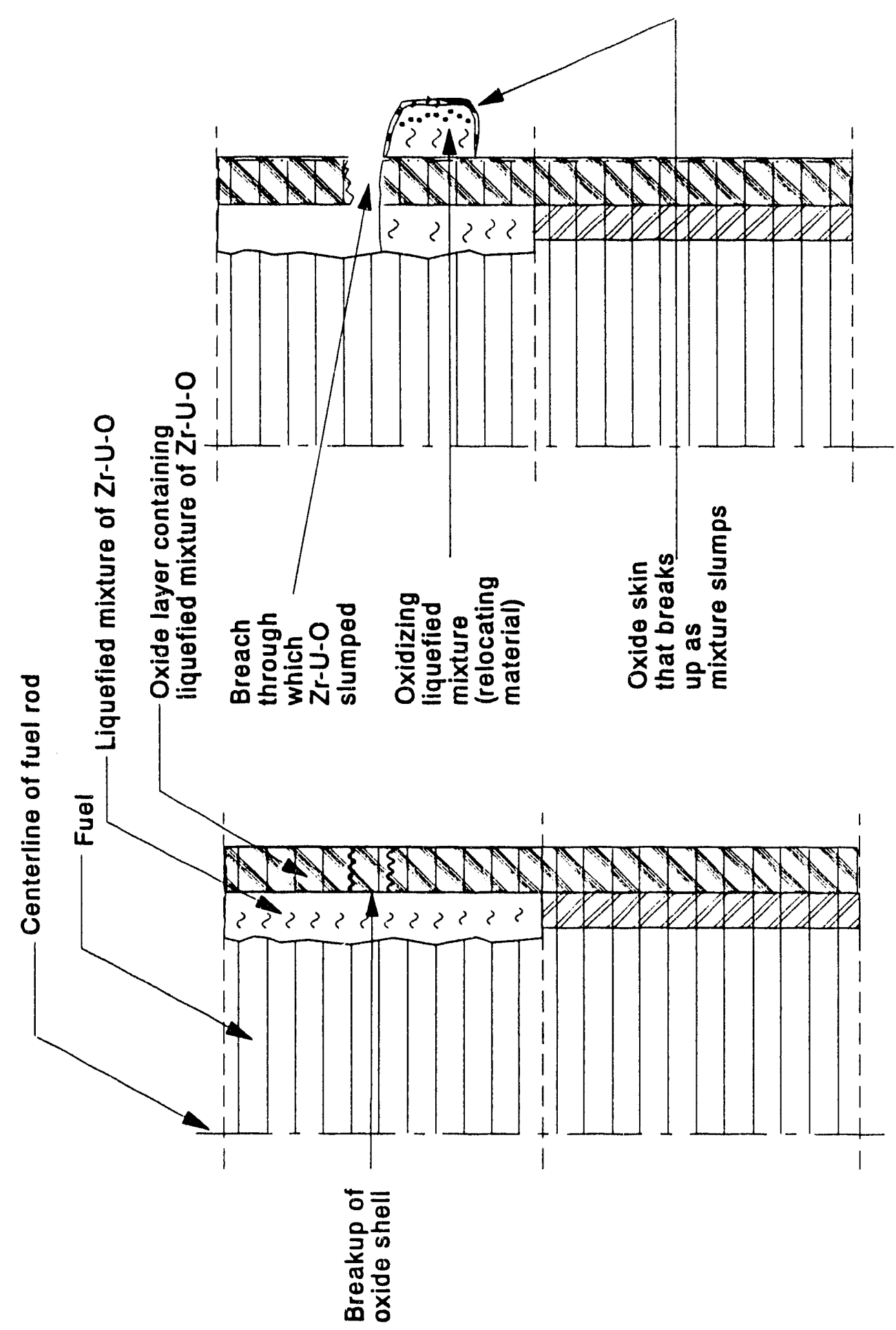

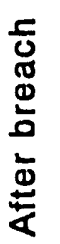

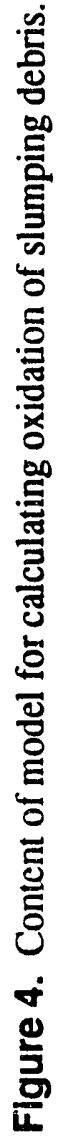


Start process for calculating oxidation of slumping debris during time step. (subroutine LIQSOL)
Identify locations at which liquefied mixtures of $\mathrm{Zr}-\mathrm{U}-\mathrm{O}$ breach oxide layer at surface of fuel rods.
For each axial node of each group of fuel rods the model for calculating failure of oxide shell (ZOFAIL) is called to determine whether oxide shell was breached during time step.

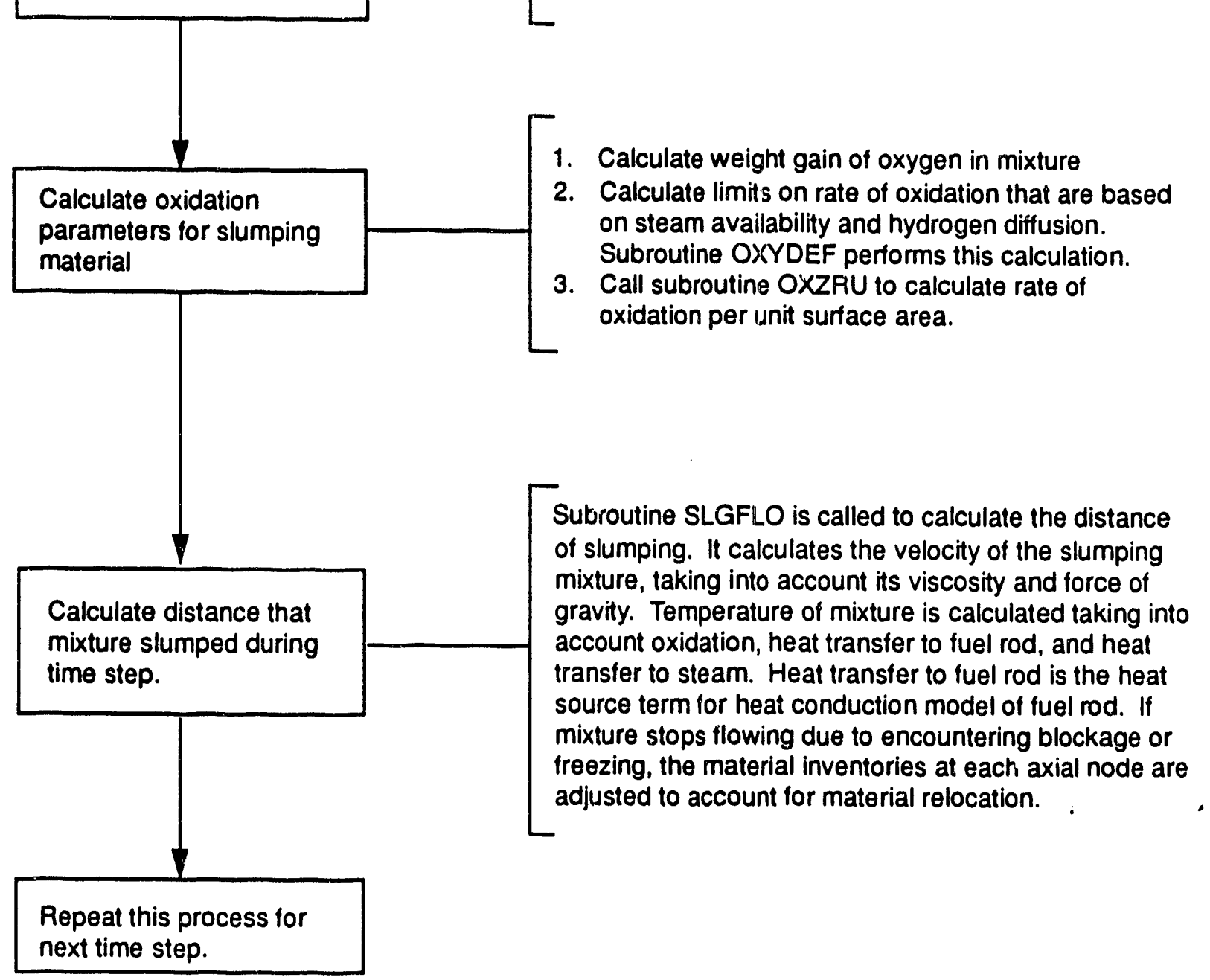

Figure 5. Annotated flow chart of the LIQSOL model for calculating overall behavior of slumping material. 
where

$$
\begin{array}{ll}
m_{U \cdot \mathrm{Zr} \cdot O}= & \text { mass of } \mathrm{UO}_{2} \text { in the melt }(\mathrm{kg}) \\
m_{t}= & \text { total mass in the melt }(\mathrm{kg}) .
\end{array}
$$

The initial weight gain is set equal to the initial oxygen in the melt at the start of slumping $(\mathrm{kg} \mathrm{O})$. The weight gain limit can be computed from Equation (11), where the masses of zircaloy and $\mathrm{UO}_{2}$ refer to the slumping material.

The basic concept of this model is that a liquefied mixture of $\mathrm{Zr}-\mathrm{U}-\mathrm{O}$ material oxidizes as it flows down the outer surface of a fuel rod. Figure 4 shows the context of the model. The left side of Figure 4 shows the configuration of a fuel rod before the slumping of a liquefied mixture of $\mathrm{Zr}-\mathrm{U}-\mathrm{O}$, and the right side shows the configuration after slumping of the liquefied mixture. Before the breach, an oxide layer contained the liquefied part of the cladding, which was metallic and oxidizing. The oxide layer also limited the rate of oxidation of the liquefied zircaloy. After the liquefied zircaloy has breached the oxide layer, it is directly exposed to steam flowing through the reactor core and can oxidize at a rapid rate. The material that has begun to slump may be temporarily coated with a thin oxide skin, but this skin is considered to break up and become absorbed into the flowing mixture.

\subsection{Model Implementation}

The model for the oxidation of slumping debris will be incorporated into the LIQSOL subroutine, which is the subroutine that models the overall behavior of slumping material. An annotated flow chart of the LIQSOL model is shown in Figure 5. The second step in LIQSOL will have the function of calculating the oxidation parameters at each axial node at which liquefied material is slumping. It is at this second step that modifications will be made to subroutine LIQSOL to call OXYDEF to calculate limits on the rate of oxidation and to call OXZRU to calculate the rate of oxidation per unit surface area of the slumping material. 


\section{OXIDATION OF POROUS DEBRIS}

Oxidation will occur in hot porous debris that contains fragments of metallic material, such as zirconium from fucl rod cladding. In the past, SCDAP/RELAP5 has not represented the oxidation of these metallic materials. Since fuel rods cannot disintegrate into porous debris until after a significant part of the cladding is oxidized or has slumped away, this simplification in modeling was to some extent justified. Nevertheless, the simplification in modeling allowed the possibility for the code to underpredict the hydrogen production that could occur during a severe accident. So a model has been developed to model the oxidation of porous debris.

\subsection{Model Framework}

The model for oxidation of porous debris will be implemented into the model that calculates the change in temperature of porous debris during a time step. This model is programmed in the subroutine HEATDB and represents, as a lumped mass, the porous debris that exists at an axial node of a fuel bundle or other group of identical fuel rods. The content of the HEATDB model is shown in Figure 6. Cladding and fuel particles are assumed to be mixed together. The size and composition of the particles are defined by the fuel rod fragmentation model, which is programmed in subroutine RUBTRN. If the fuel rods have been heated to a temperature greater than the melting temperature of the cladding, then the cladding dissolves fuel. If the fuel rods later cool and fragment, the particles of cladding are composed of a mixture of $\mathrm{Zr}-\mathrm{U}-\mathrm{O}$. The conduction of heat from a particle to its neighboring particles is not represented; all of the particles in the lumped mass are assumed to be at the same temperature, which is considered to be uniform within each particle. The temperature change of the lumped mass is calculated taking into account the

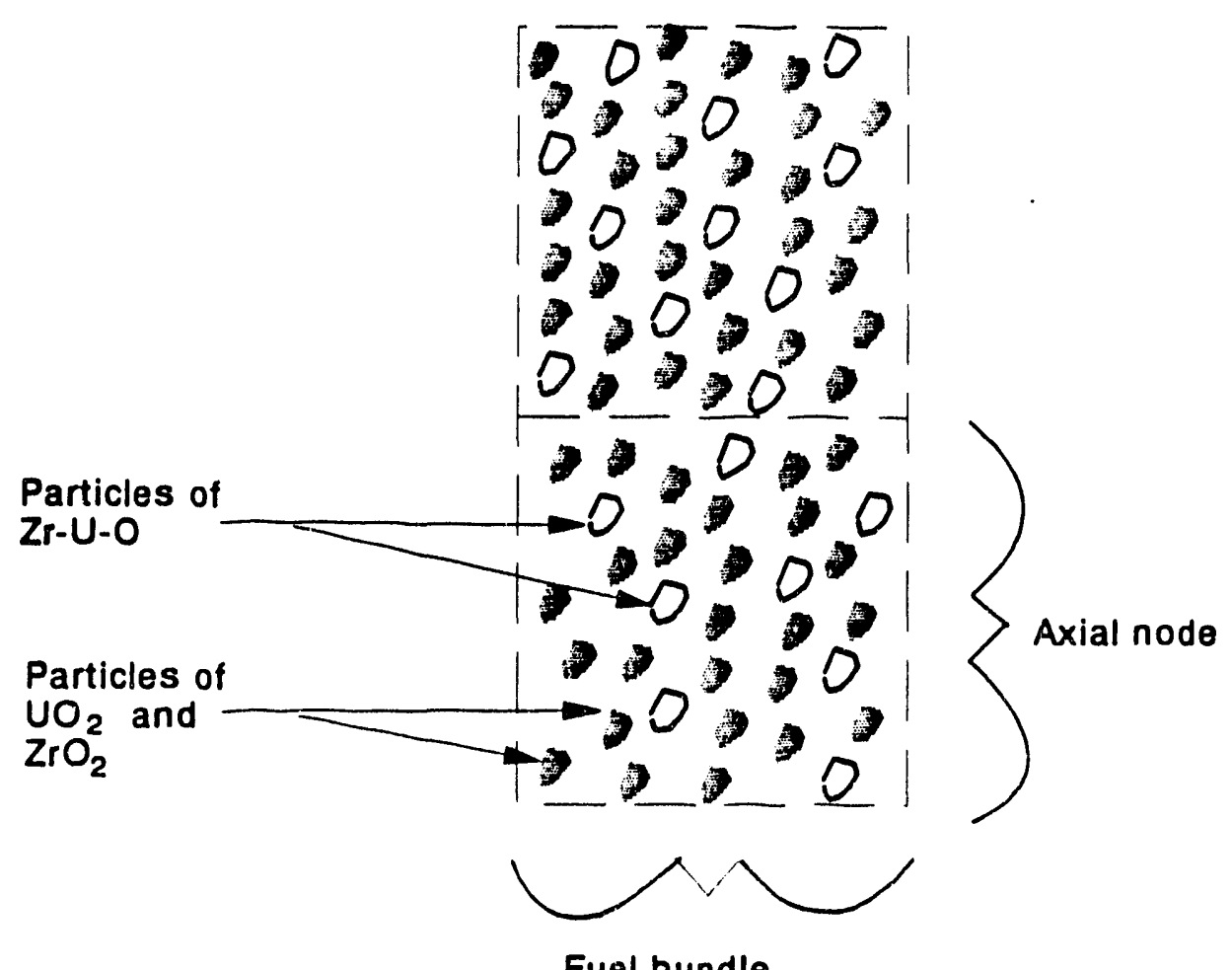

Fuel bundle

M167-BDR-0293-012

Flgure 6. Content of model for oxidation of porous debris. 
decay heat in it and the rate of heat transfer between it and the fluid flowing through it. The model currently does not calculate the oxidation of the particles that constitute the porous debris. The model will be extended to calculate the oxidation of the metallic particles within the porous debris and to calculate the effect that oxidation has on the thermal response of the porous debris.

\subsection{Basic Concepts and Assumptions}

The same concepts for oxidation of a unit surface area of cohesive debris (presented in Section 2.2) will be applied for the oxidation of a unit surface area of porous debris. The model will consider the oxidation of particles that are composed of cladding material and particles that are composed only of fuel. The heat generated per unit surface area of debris particles will be calculated by Equation (7). The model for calculating the temperature of the porous debris (HEATDB model) requires the volumetric heat generation in the porous debris. The volumetric heat generation due to oxidation will be calculated by the equation

$$
P_{v}=A_{m s} Q_{m}+A_{U s} Q_{U}
$$

where

$$
\begin{aligned}
& P_{v} \quad=\quad \text { volumetric heat generation due to oxidation in porous debris }\left(\mathrm{W} / \mathrm{m}^{3}\right) \\
& A_{m s}=\text { surface area of debris particles that are composed of } \mathrm{Zr} \text { or } \mathrm{Zr}-\mathrm{U}-\mathrm{O}\left(\mathrm{m}^{2} / \mathrm{m}^{3}\right) \\
& Q_{m} \quad=\quad \text { heat generated at surface of particles composed of } \mathrm{Zr} \text { or } \mathrm{Zr}-\mathrm{O}-\mathrm{U} \text { due to oxidation. } \\
& \text { This variable is calculated by Equation (7) with } f \text { equal to the mass fraction of } \\
& \mathrm{UO}_{2} \text { in the } \mathrm{Zr}-\mathrm{U}-\mathrm{O} \text { particles }\left(\mathrm{W} / \mathrm{m}^{2}\right) \\
& A_{U s}=\quad \text { surface area of debris particles that are composed of } \mathrm{UO}_{2}\left(\mathrm{~m}^{2} / \mathrm{m}^{3}\right) \\
& Q_{U}=\text { heat generated at surface of particles that are composed of } \mathrm{UO}_{2} \text {. This variable is } \\
& \text { calculated by Equation (7) with } f \text { equal to } 1\left(\mathrm{~W} / \mathrm{m}^{2}\right) \text {. }
\end{aligned}
$$

A more detailed representation of the geometry of porous debris than is currently modeled is required in order to model the oxidation of porous debris. Previously, only the average particle size of debris was required. Now, the particle size and shape of each material constituent are required. Since it is beyond the scope of this report to develop a model of the disintegration of fuel rods that calculates the size and shape of the debris resulting from disintegration, an ad hoc assumption is required of the size and shape of a disintegrated fuel rod. The assumption that will be applied to define the configuration of a disintegrated fuel rods is shown in Figure 7. The left side of Figure 7 shows the configuration of the rod before disintegration, and the right side of Figure 7 shows the configuration of the rod after disintegration. When the fuel rod is still intact, it consists of three material regions: cladding oxide, metallic cladding with dissolved fuel, and fuel. Upon disintegration, each of the material regions is assumed to separate from each other and break up into particles that are approximately cubic in shape. In the outer two regions, the width of one face of the particle is assumed to equal the thickness of the annulus of the material region just before disintegration. This assumption on particle size is reasonable in view of the small particles observed in the portion of the TMI-2 core that was quenched. The average particle size of the debris in this portion of the core was $0.87 \mathrm{~mm}$, which is of the same magnitude of size as the as-fabricated cladding thickness, which was $0.67 \mathrm{~mm}$.

The surface area of the zircaloy and fuel particles per unit volume of debris is required in order to calculate the volumetric rate of heat generation due to oxidation. The surface area will be calculated in two steps. First, the surface area per particle will be calculated; second, the number of particles per unit volume of porous debris will be calculated. The surface area per metallic particle (particles composed of $\mathrm{Zr}$ or $\mathrm{Zr}-\mathrm{U}-\mathrm{O}$ ) will be calculated by the equation 

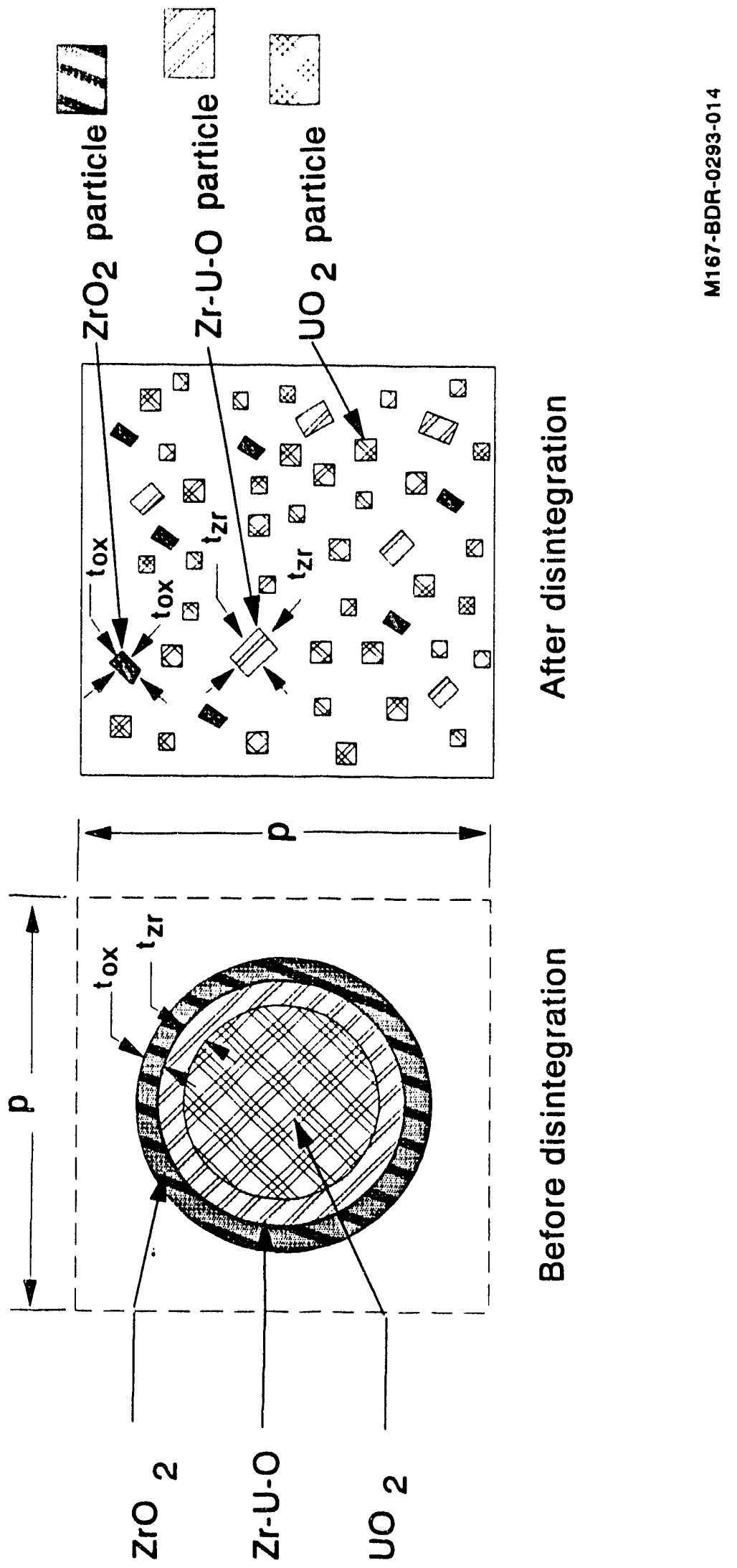

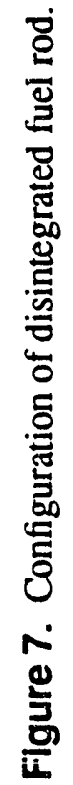


$A_{p}=6 t_{Z r}^{2}$

where

$$
\begin{array}{lll}
t_{\mathrm{Zr}} & = & \text { thickness of annular region of } \mathrm{Zr}-\mathrm{U}-\mathrm{O} \text { (cladding and dissolved fuel) }\left(\mathrm{m}^{2}\right) \\
A_{p} & = & \text { surface area of one particle of metallic material }\left(\mathrm{m}^{2}\right) .
\end{array}
$$

The volume of one particle is calculated by the equation

$V_{p}=t_{Z r}^{3}$

where $V p$ is the volume of one particle $\left(\mathrm{m}^{3}\right)$. The number of particles per unit height of one fuel rod is calculated by the equation

$n_{r}=\frac{\pi\left(r_{o}^{2}-r_{i}^{2}\right)}{V_{p}}$

where

$$
\begin{array}{lll}
n_{r} & = & \text { number of particles per unit height of one fuel rod } \\
r_{o} & = & \text { outer radius of annular region of } \mathrm{Zr}-\mathrm{U}-\mathrm{O}(\mathrm{m}) \\
r_{i} & = & \text { inner radius of annular region of } \mathrm{Zr}-\mathrm{U}-\mathrm{O}(\mathrm{m}) \\
\left(r_{o}-r_{i}\right)= & t_{\mathrm{Zr}}=\text { thickness of annular region of } \mathrm{Zr}-\mathrm{U}-\mathrm{O}(\mathrm{m}) .
\end{array}
$$

The core volume per unit height of fuel rod is given by the equation

$V_{c}=P^{2}$

where

$$
\begin{array}{lll}
V_{c} & = & \text { volume of core per unit height of one fuel } \mathrm{rod}\left(\mathrm{m}^{3} / \mathrm{m}\right) \\
P & = & \text { pitch of fuel rods }(\mathrm{m}) .
\end{array}
$$

The number of particles per unit of core volume occupied by fuel rods is then given by the equation $n_{p}=\frac{n_{r}}{V_{c}}$

where $n_{p}$ is the number of particles per unit volume of core occupied by fuel rods (particle $/ \mathrm{m}^{3}$ ).

A compaction or expansion of materials may take place when fuel rods disintegrate, causing the number of particles per unit volume of debris to be different than the number of particles per unit of core volume occupied by fuel rods. The ratio of these two particle densities is given by the equation

$$
\gamma=\frac{\varepsilon_{r}}{\varepsilon_{d}}
$$


where

$$
\begin{array}{lll}
\gamma & = & \begin{array}{l}
\text { ratio of particle density at porosity of intact core to particle density at porosity of } \\
\text { disintegrated core }
\end{array} \\
\varepsilon_{\mathrm{T}} & = & \text { porosity of core with intact fuel rods } \\
\varepsilon_{\mathrm{d}} & = & \text { porosity of porous debris. }
\end{array}
$$

The porosity of porous debris is assumed to equal the average porosity of the upper debris bed in the postaccident TMI-2 reactor core, which was $0.54 .^{5}$ The porosity of a core with intact fuel rods is given by the equation

$$
\varepsilon_{r}=1-\frac{\pi r_{c}^{2}}{P^{2}}
$$

where $r_{c}$ is the outer radius of as-fabricated fuel rods $(\mathrm{m})$. Typical values of $r_{c}$ and $P$ are $0.5461 \times 10^{-2}$ and $1.4427 \times 10^{-2} \mathrm{~m}$, respectively. So, the typical value of $\varepsilon_{\mathrm{T}}$ is 0.55 . This value is similar to the porosity measured for the upper debris bed in the TMI-2 core. The similar values indicate that there is no significant compaction or expansion of that portion of a reactor core in which the fuel rods disintegrate. Thus, the parameter $\gamma$ will be set equal to 1 .

The surface area of metallic particles per unit volume of debris is then given by the equation

$$
A_{m s}=n_{p} A_{p}=\frac{6 \pi\left(r_{o}+r_{i}\right)}{P^{2}}
$$

where $A_{m s}$ is the surface area of metallic debris per unit volume of debris $\left(\mathrm{m}^{2} / \mathrm{m}^{3}\right)$. This variable is applied in Equation (14).

A perspective of the amount of surface area of $\mathrm{Zr}$ particles in a disintegrated core can be obtained by comparing this surface area to that of the surface area of $Z_{r}$ in an intact core. In an intact core with single-sided oxidation, the surface of $\mathrm{Zr}$ exposed to steam per unit volume of core is approximately

$$
A_{c}=\frac{\pi\left(r_{o}+r_{i}\right)}{P^{2}}
$$

where $A_{c}$ is the surface area of metallic material exposed to coolant per unit volume of core $\left(\mathrm{m}^{2} / \mathrm{m}^{3}\right)$. By taking the ratios of $A_{m s}$ to $A_{c}$, it is seen that when fuel rods disintegrate, the surface area exposed to steam increases by a factor of six for intact rods with single-sided oxidation.

The surface area of fuel particles per unit volume of porous debris [variable $A_{U s}$ in Equation (14)] will be calculated in a manner similar to that for metallic particles.

Some debris models, such as those for flow resistance, require an effective particle size for a debris bed with a range of particle sizes. The three types of material in the porous debris--namely, $\mathrm{ZrO}, \mathrm{Zr}-\mathrm{U}-\mathrm{O}$ (metallic cladding and dissolved $\mathrm{UO}_{2}$ ) and $\mathrm{UO}_{2}$--each have a different particle size. The Fair-Hatch formula ${ }^{7}$ will be applied to calculate the effective particle diameter. This formula is

$$
d_{e}=f_{s}\left(\sum_{i=1}^{3} \frac{f_{i}}{d_{i}}\right)^{-1}
$$


where

$$
\begin{array}{lll}
d_{e} & = & \text { elfective diametcr of particles }(\mathrm{m}) \\
f_{s} & = & \text { shape factor } \\
f_{i} & = & \begin{array}{l}
\text { volume fraction of material type } \mathrm{i} . \text { For } \mathrm{i}=1, \text { the material is zircaloy; for } \mathrm{i}=2, \\
\text { the material is } \mathrm{Zr}-\mathrm{U}-\mathrm{O} ; \text { and for } \mathrm{i}=3, \text { the material is } \mathrm{UO}_{2} .
\end{array} \\
d_{i} & =\quad \text { size of particles in material type } \mathrm{i}(\mathrm{m}) .
\end{array}
$$

The shape factor $f_{s}$ is 0.78 for rough particles and 1.0 for spheres; the shape factor for rough particles will be applied. The value of $d_{1}$ is equal to $t_{o x}$ (the thickness of the shell of $\mathrm{ZrO}_{2}$ ). The value of $d_{2}$ is equal to ${ }_{\mathrm{Z} z}$ (the thickness of the annulus of $\mathrm{Zr}-\mathrm{U}-\mathrm{O}$ ). The value of $d_{3}$ is $0.87 \mathrm{~mm}$, which is the average size of the debris particles in the upper debris bed in the postaccident TMI-2 reactor core.

\subsection{Model Implementation}

The model for oxidation of debris will be implemented into the HEATDB model, which calculates the thermal response of the porous debris. The HEATDB model currently calculates the volumetric heat generation in the debris due to decay of fission products in the debris. The model will be extended to calculate the volumetric heat generation due to oxidation, add this heat generation to the heat generation due to fission product decay, and then apply the sum of these two sources of heat in calculating the thermal response of the debris.

The OXZRU model developed for calculating the oxidation of cohesive debris will also be used to calculate the oxidation of porous debris. This model is described in Section 2.3. Given a unit surface area of debris, the model calculates the weight gain in oxygen and the heat generation in the debris as a function of the debris temperature and its composition and as a function of the conditions of the fluid in contact with the debris. Subroutine HEATDB will be extended to call subroutine OXZRU and to apply its output in the calculation of the rate of heatup of the debris. Since the debris at an axial node is represented as a lumped mass, the heat generation due to oxidation of metallic particles will be assumed to be uniformly distributed within the axial node. This heat generation will be added to the uniformly distributed value of the heat generation from fission product decay to obtain the overall rate of heat generation in the porous debris. The hydrogen produced by oxidation in the porous debris will be added to the source term for noncondensable gases in the RELAP5 part of the code. 


\section{MATERIAL INTERACTIONS}

This section describes a model ior the chemical reaction that takes place between the stainless steel cladding of a pressurized water reactor (PWR) control rod and the $\mathrm{Zr}$ guide tube adjacent to it. This chemical reaction causes the cladding and guide tube to liquefy at temperatures below their respective standalone meluing temperatures. Previously, this chemical reaction was not modeled; and simplifying assumptions were required to calculate the meltdown of PWR control rods. Liquefied absorber material was assumed to stay in place until the temperature of the stainless steel cladding exceeded its stand-alone melting temperature. When this temperature threshold was reached, the stainless steel cladding was assumed to instantly dissolve the $\mathrm{Zr}$ guide tubs, resulting in the release and slumping of the liquefied materials. These deficiencies in mocieling will be resolved by the implementation of a model for the chemical reaction between the absorber cladding anci guide tube.

\subsection{Model Framework}

The extension to model the material interaction between the stainless steel cladding of a PWR control rod and its zircalny guide tube will be implemented into the model for the overall behavior of control rods, which is programmed in the subroutine CYLIN. The material whose behavior is being calculated by the CYLIN model is shown in Figure 8. The model currently calculates the oxidation, meltdown, and thermal response of the control rod. It calculates the melting of absorber material and stainless steel in response to heatu $p$, but it does not calculate the liquefaction of stainless steel and $\mathrm{Zr}$ due to chemical reaction. The inodel will te extended to calculate this liquefaction that is induced by chemical reaction. A flow chart of the CYLIN model is shown in Figure 9.

\subsection{Basic Concepts and Assumptions}

This model calculates the growth of a zone of liquefied material due to the chemical reaction between the iron in the stainless steel cladding of the absorber material and the zirconium in the control rod guide tube. The situation in which the model is applied is shown in Figure 8. The stainless steel cladding of the absorber material is assumed to be in contact with the guide tube that surrounds it. The chemical reaction that takes place between the stainless steel and the zirconium is a strong function of temperature. Since the iemperature of the control rod varies in the axial direction, the radial extent of the reaction zone will also vary in the axial direction. The objective of the model is to calculate, as a function of time, the inner and outer radii of the reaction zone. If the outer radius of the reaction zone reaches the outer radius of the guide tube, then a breach is formed: and liquefied material will slump through the breach.

The outer radius of the reaction zone will be calculated as a function of time by the equation ${ }^{8}$

$$
r_{\text {soN } 2}=\left[r_{\text {soN } 1}^{2}+A \exp \left(-\frac{B}{R T}\right) \Delta t\right]^{0.5}
$$

where

$\begin{array}{lll}r_{\text {soN2 }}= & \text { outer radius of reaction zone at end of time step for axial node } \mathrm{N}(\mathrm{m}) \\ r_{\text {soN1 }}= & \text { outer radius of reaction zone at start of time step }(\mathrm{m}) \\ A, B & = & \begin{array}{l}\text { coefficients that are a function of temperature and are defined as } 2.78 \mathrm{e}-15 \mathrm{~m}^{2} / \mathrm{s} \\ \text { and }-642864, \text { respectively }\end{array} \\ R & = & \text { universal gas constant }\left(8.314 \mathrm{~Pa} \cdot \mathrm{m}^{3} /(\mathrm{g}-\mathrm{mole} \cdot \mathrm{K})\right. \\ T & = & \text { temperature of reacting materials }(\mathrm{K})\end{array}$




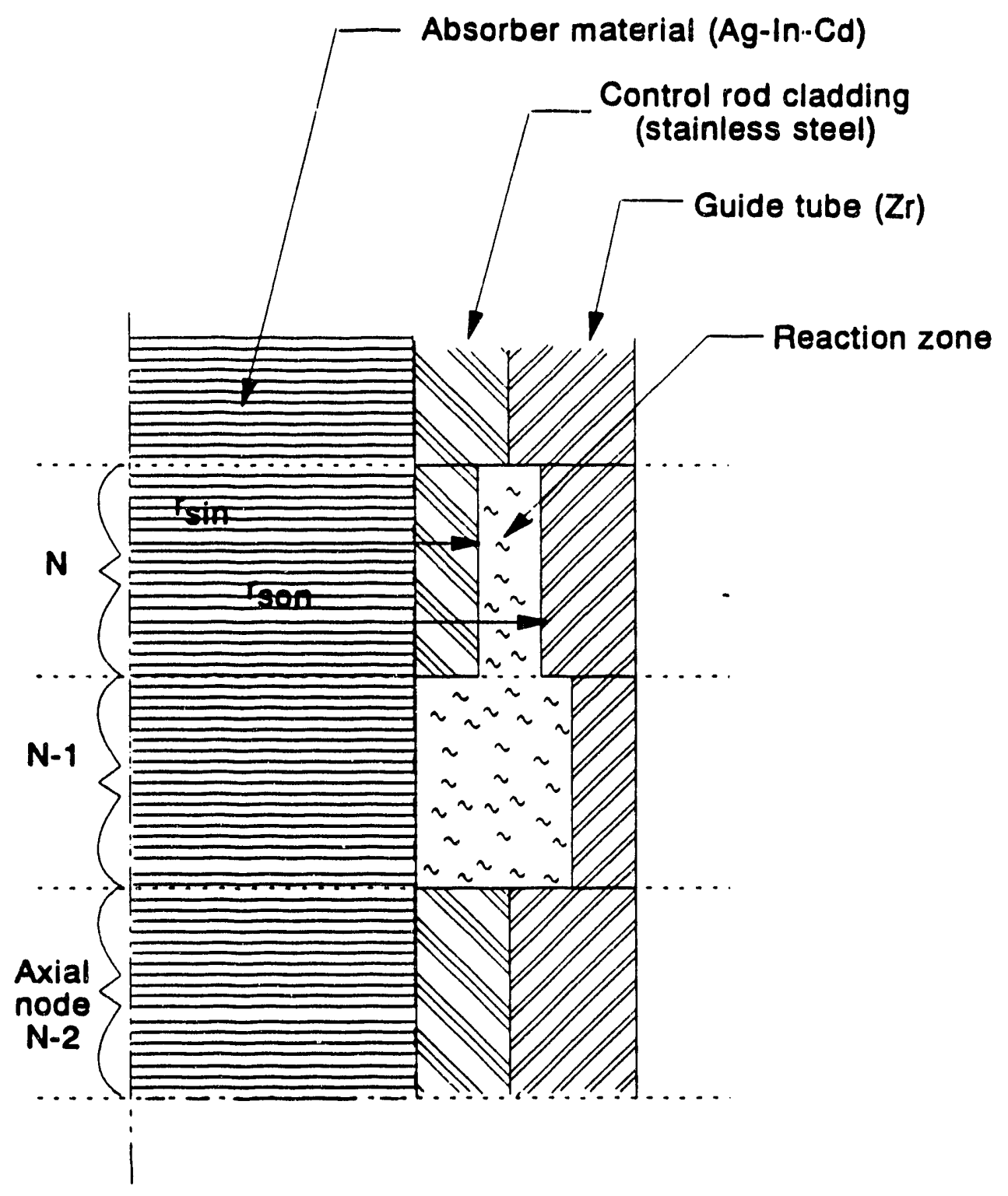

MI67-8OR-1292-004

Flgure 8. Chemical reaction between control rod cladding and guide tube. 

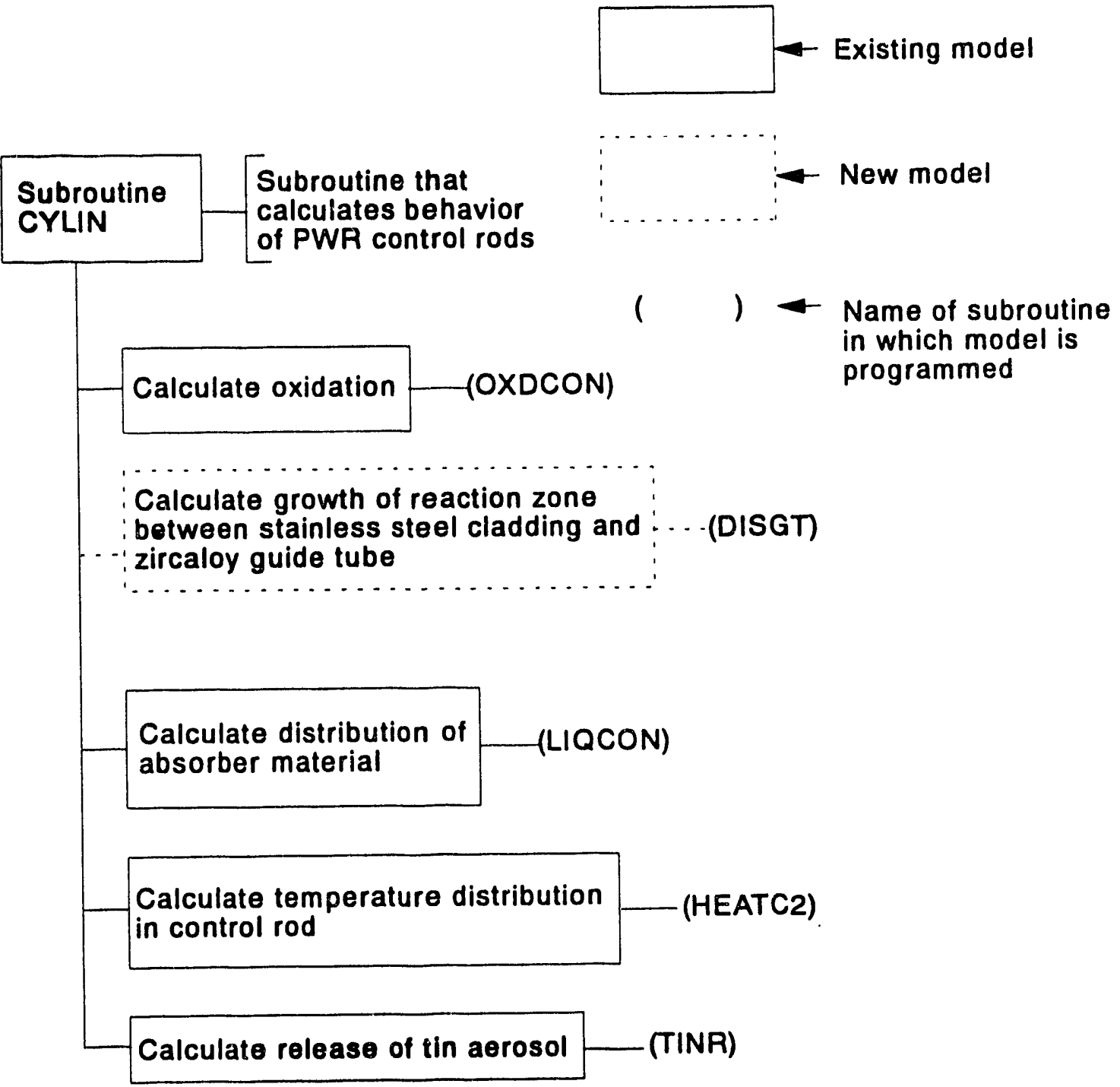

M167-BDR-1292-003A

Figure 9. Annotated flow chart of models in calculation of PWR control rod behavior. 


$$
\Delta t \quad=\quad \text { time step size (s). }
$$

The equation for calculating the inner radius of the reaction zone, namcly variable $r_{\sin }$ of Figure 8 , is the same as that used to calculate the outer radius, except that the coellicients $A$ and $B$ are defined as $1.08 \mathrm{e}-15 \mathrm{~m}^{2} / \mathrm{s}$ and -688790 (unitless).

The binary alloy phase diagram of the Fe- $\mathrm{Zr}$ system will be used to limit the rate of growth of the reaction zone to that which keeps the material in the reaction zone liquefied. The phase diagram of the Fe$\mathrm{Zr}$ system is shown in Figure 10. The symbol $\mathrm{L}$ in the top part of the diagram designates the phase that is liquid. The curve below $L$ defines the boundary between a liquefied and solidified mixture as a function of the temperature of the mixture and the fraction of $\mathrm{Fe}$ in the mixture. The curve indicates that a liquefied reaction zone begins when the temperature of the control rod cladding and guide tube exceeds $1201 \mathrm{~K}$. If the $\mathrm{Fe}$ content in the reacted zone stays at 24 at.\% $\mathrm{Fe}$, then the reaction zone would continue to grow at the rate predicted by the kinetics equations. If, for example, the fraction of $\mathrm{Fe}$ in the zone increased to 40 at.\% $\mathrm{Fe}$, then the reaction zone in the control rod cladding could not continue until the temperature increased to $1740 \mathrm{~K}$ or until enough $\mathrm{Zr}$ had liquefied that the fraction of $\mathrm{Fe}$ in the mixture was reduced to 24 at.\%.

\subsection{Model Implementation}

A MATPRO subroutine named DISGT will be developed to calculate the growth of the reaction zone. This subroutine will be parallel to the subroutine named DISUO2, which calculates the growth of the reaction zone between zirconium and $\mathrm{UO}_{2}$. The input arguments to DISGT are the temperature of the reaoting materials, the size of the time step, and the inner and outer radii of the reaction zone at the start of the time step. The temperature distribution within the reacting materials will be assumed to be uniform. The output arguments to DISGT will be the inner and outer radii of the reaction zone at the end of the time step. A call to the new subroutine DISGT will be placed in the model for PWR control rods, which is programmed in the subroutine named CYLIN. A flow chart of the CYLIN model is shown in Figure 9.

A new MATPRO subroutine will also be programmed to define the liquidus-solidus line in the binary alloy phase diagram of the system $\mathrm{Fe}-\mathrm{Zr}$. Given the at.\% of $\mathrm{Fe}$ is 4 mixture of $\mathrm{Zr}$ and $\mathrm{Fe}$, the subroutine will return the temperature at the liquidus/solidus boundary. The subroutine will also return an argument to indicate whether more $\mathrm{Fe}$ or $\mathrm{Zr}$ needs to react at this temperature in order to keep the reacted zone liquefied. 


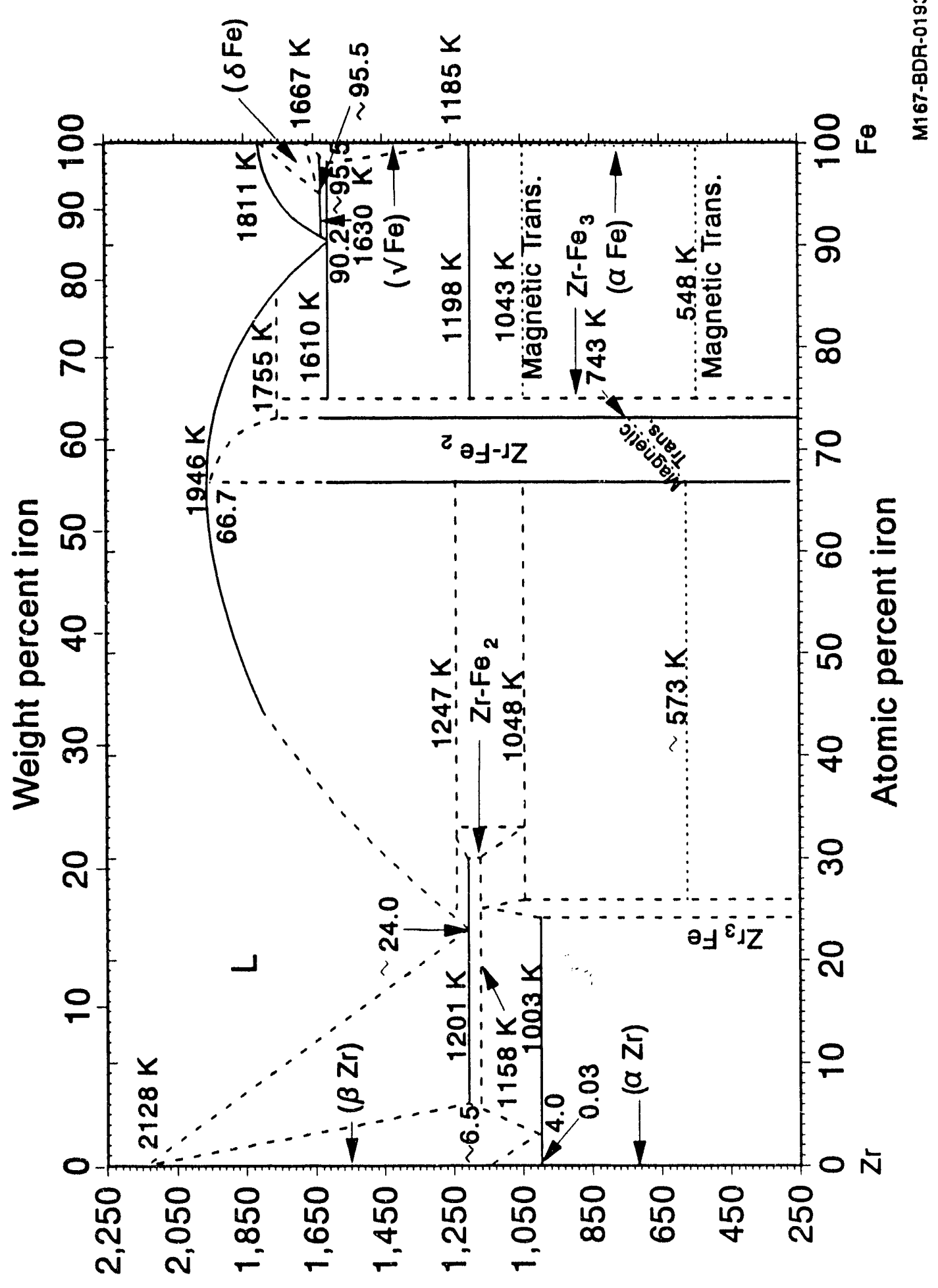

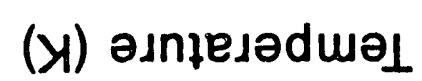




\section{REFERENCES}

1. C. M. Allison et al, SCDAPIRELAPS Code Manual, Volume 2: SCDAP Code Structure, Systems Models, and Solution Methods (Draft), NUREG/CR-5273, EGG-2555, Revision 1, September 1990.

2. E. W. Coryell et al, Model Completion Report: SCDAP/RELAP5 Reflood Oxidation (Draft for Review), EGG-SSRE-10307, July 1992.

3. J. K. Hohorst et al., SCDAPIRELAP5/MOD2 Code Manual, Volume 4: MATPRO--A Library of Materials Properties for Light-Water-Reactor Accident Analysis, NUREG/CR-5273, EGG-2555. February 1990.

4. J. T. Prater and E. L. Courtright, Properties of Reactor fuel Materials at High Temperature, NUREG/CR-4891, July 1987.

5. D. W. Akers et al., TMI-2 Core Debris Grab Samples--Examination and Analysis, GEND-INF-975, September 1986.

6. S. Hagen et al, "Out-of-Pile Experiments on Severe Fuel Damage Behavior of LWR Fuel Elements (CORA Program)," paper IAEA-SM-296/26, International Symposium on Severe Accidents in Nuclear Power Plants, Sorrento, Italy, March 21-25, 1988.

7. R. J. Lipinski, $A$ Model for Boiling and Dryout in Particle Beds, NUREG/CR-2646, SAND820765, June 1982.

8. P. Hofmann and M. Machiewicz, Chemical Behavior of (Ag, In,Cd) Absorber Rods in Severe Accidents, KfK 4670, CNEA NT-16189, August 1990. 

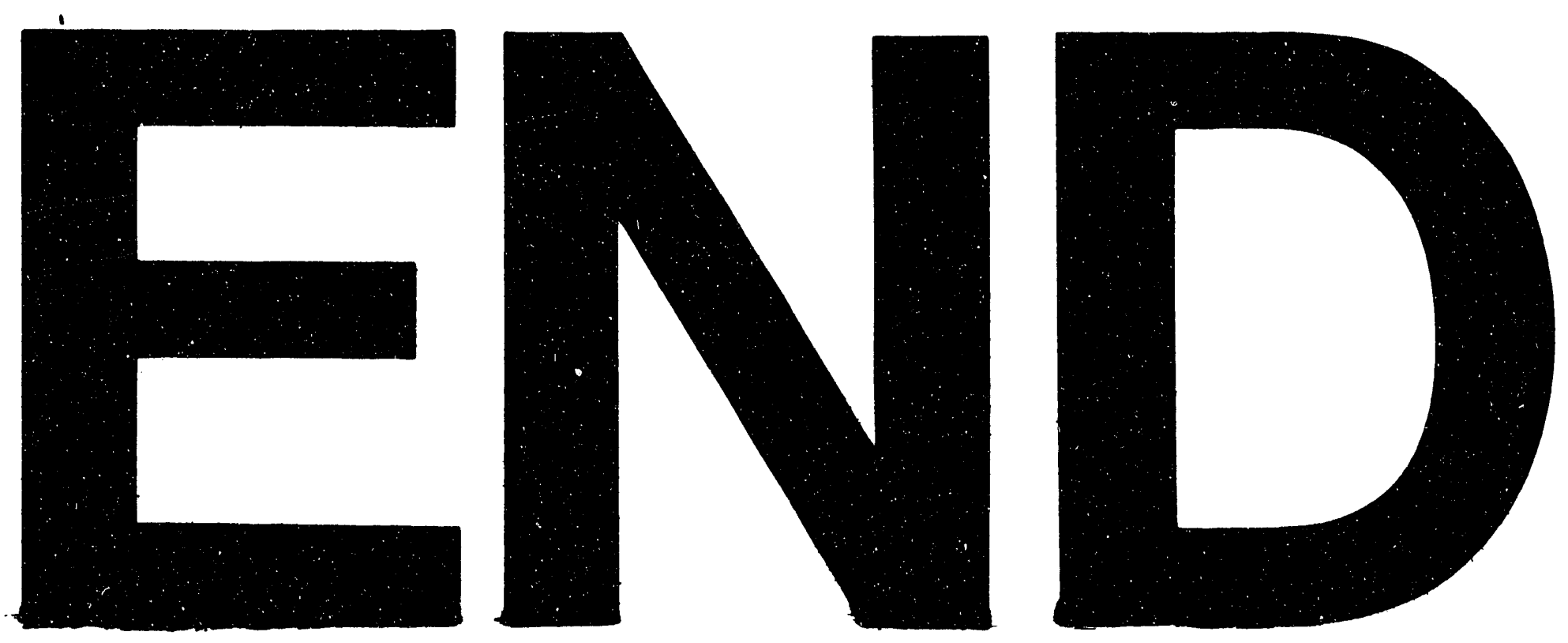

X
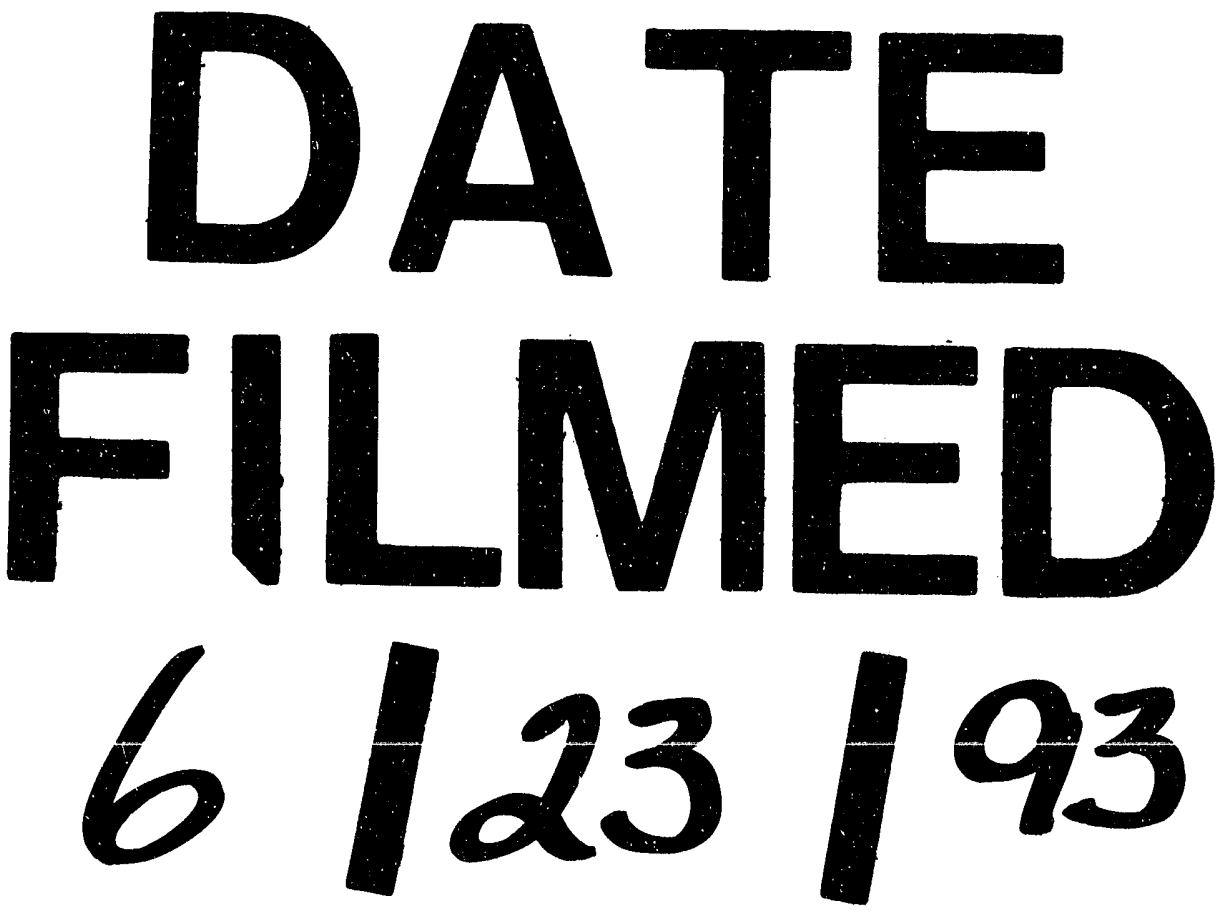
